\title{
Observations of the 2008 Kasatochi volcanic $\mathrm{SO}_{2}$ plume by CARIBIC aircraft DOAS and the GOME-2 satellite
}

\author{
K.-P. Heue ${ }^{1}$, C. A. M. Brenninkmeijer ${ }^{1}$, T. Wagner $^{1}$, K. Mies ${ }^{1}$, B. Dix ${ }^{2}$, U. Frieß ${ }^{3}$, B. G. Martinsson ${ }^{4}$, F. Slemr ${ }^{1}$, and \\ P. F. J. van Velthoven ${ }^{5}$ \\ ${ }^{1}$ Max-Planck-Institut für Chemie (MPI), Mainz, Germany \\ ${ }^{2}$ Department of Chemistry and Biochemistry, University of Colorado, Boulder, USA \\ ${ }^{3}$ Institut für Umweltphysik, Universität Heidelberg, Heidelberg, Germany \\ ${ }^{4}$ Avdelningen för kärnfysik, Lunds universitet, Lund, Sweden \\ ${ }^{5}$ Koninklijk Nederlands Meteorologisch Instituut (KNMI), De Bilt, The Netherlands
}

Received: 7 October 2009 - Published in Atmos. Chem. Phys. Discuss.: 12 January 2010

Revised: 11 May 2010 - Accepted: 12 May 2010 - Published: 21 May 2010

\begin{abstract}
The 2008 Kasatochi volcanic eruption emitted $\approx 1.5-2.5 \mathrm{Tg} \mathrm{SO} \mathrm{S}_{2}$ into the upper troposphere and lower stratosphere. Parts of the main volcanic plume (gases and particles) reached central Europe a week after the eruption and were detected there by the CARIBIC (Civil Aircraft for Regular investigation of the Atmosphere based on an Instrument Container) flying observatory. The plume was also observed by the GOME-2 satellite instrument, only a few hours after the CARIBIC aircraft had crossed the plume, thus giving a unique opportunity to compare results. Trajectories and local wind speeds are investigated in detail using the GOME-2 and CARIBIC observations for better comparison of the results from these two observational systems. A comparison of the satellite spatial pattern with the local observations of the wind speed and the trajectory model TRAJKS showed a slight discrepancy, which has to be considered for satellite validation. Hence, it appears that detailed analyses of wind speeds are required. Emitted and secondary particles, partly measured and sampled by the CARIBIC in situ instruments, affected the DOAS $\mathrm{SO}_{2}$ measurements, of both CARIBIC and GOME-2. Overall GOME-2 and the CARIBIC $\mathrm{SO}_{2}$ measurements agree very well. The major uncertainties remain the actual wind speed needed to properly correct for the advection of the plume between the different overpass times and effects of aerosols on DOAS retrievals. The good agreement can be seen as validation for both GOME-2 and CARIBIC DOAS observations.
\end{abstract}

Correspondence to: K.-P. Heue (klaus-peter.heue@mpic.de)

\section{Introduction}

Components of the Kasatochi plume (besides particles, remnants of the 1.5 to $2.5 \mathrm{Tg} \mathrm{\textrm {SO } _ { 2 }}$ emitted; e.g., Richter et al., 2009) were detected by several instruments aboard the CARIBIC observatory (Civil Aircraft for Regular investigation of the Atmosphere based on an Instrument Container, http://www.caribic-atmospheric.com) (Brenninkmeijer et al., 2006) over Europe during a flight from Chennai (India) back to Frankfurt (Germany) on 15 August 2008. Besides enhanced particle number densities and a higher carbon and sulphur content of total aerosol (Martinsson et al., 2009) a strong increase in sulphur dioxide column densities was observed by the DOAS (Differential Optical Absorption Spectroscopy) instrument (Platt and Stutz, 2008). Although the CARIBIC flying laboratory has been in operation since 1997 (with an interruption from 2002-2004), the Kasatochi eruption in August 2008 was the first significant volcanic plume observed in this period, as witnessed by strongly elevated sulphur-to-ozone ratios (Martinsson et al., 2009). Also with similar DOAS instruments (e.g. Heue et al., 2005) build for research aircraft, $\mathrm{SO}_{2}$ was only detected in indutrial plumes (Wang et al., 2005) rather than volcanic ones.

By the time the plume was detected, while the aircraft approached Frankfurt airport, it had already travelled around half of the northern hemisphere at about $50^{\circ} \mathrm{N}$. The plume's paths can be retrieved directly from $\mathrm{SO}_{2}$ column densities observed by several satellite UV-spectrometers e.g. OMI (Ozone Monitoring Instrument, Levelt et al. , 2006), SCIAMACHY (Scanning Imaging Absorption Spectrometer for Atmospheric CHartographY, Bovensmann et al., 1999), or

Published by Copernicus Publications on behalf of the European Geosciences Union. 
GOME-2 (Global Ozone Monitoring Experiment-2, Callies et al., 2000). Here GOME-2 data will be compared with the rather fortuitous observations of the plume by CARIBIC. This is because the temporal difference in the observation is small compared to SCIAMACHY or OMI.

First we describe the CARIBIC DOAS instrument and its measurements followed by a description of the GOME-2 data. A brief interpretation of the CARIBIC DOAS data is given, additional CARIBIC measurements are also considered. In this way the plume height and thickness can be estimated. As the overpass times of the two observing platforms differed by more than $3 \mathrm{~h}$ forward trajectories (Scheele et al., 1996; Stohl et al., 2001) are included in the comparison. Because of a slight inconsistency between GOME-2 and CARIBIC $\mathrm{SO}_{2}$ results a more detailed study of local wind pattern was performed, which resulted in better agreement. The retrieval of the aerosol optical properties is addressed and external information is included, however the influence of the aerosols on the $\mathrm{O}_{4}$ slant column is outweighed by a large cloud cover below the CARIBIC flight level.

\section{Description of the instruments}

\subsection{CARIBIC instrumentation}

CARIBIC is based on a Lufthansa Airbus A340-600 retrofitted with a 3 probe (trace gases, water and aerosol) inlet system. The aircraft carries the instrument container on a monthly basis during four consecutive regular passenger flights for 2-3 days. $\mathrm{CO}, \mathrm{CO}_{2}, \mathrm{O}_{3}, \mathrm{NO}, \mathrm{NO}_{\mathrm{y}}$, some organic compounds (e.g. acetone), mercury, total and gaseous water and aerosols are measured in real time. In addition, 28 air samples and 16 aerosol samples are taken for retrospective laboratory analysis of a host of trace gases (Schuck et al., 2009) and aerosol elemental composition, respectively (Nguyen et al., 2006). A video camera in the inlet pylon takes a frame every second for post flight cloud cover analysis. Also the miniature DOAS telescopes are mounted in this pylon. The instruments are maintained and operated by nine scientific groups from institutes in Europe (http: //www.caribic-atmospheric.com, July 2009).

\subsection{The DOAS instrument on CARIBIC}

DOAS (Differential Optical Absorption Spectroscopy) is a well established technique (Platt and Stutz, 2008) and was implemented in CARIBIC to provide a true remote sensing capability to this airborne platform (Dix et al., 2009). The technique is based on the fact that several atmospheric trace gases have characteristic absorption structures in the UVvisible wavelength range. These spectral fingerprints can be used to detect and quantify the trace gases by doing a spectral analysis of scattered or reflected sunlight. Thereby $\mathrm{NO}_{2}$, $\mathrm{HCHO}, \mathrm{HONO}, \mathrm{BrO}, \mathrm{OClO}, \mathrm{O}_{3}, \mathrm{SO}_{2}$ and $\mathrm{O}_{4}$ can be detected simultaneously. The CARIBIC DOAS system com- prises three spectrometers (USB 2000 from Ocean Optics) inside a rack unit in the container, each connected to one of the three small telescopes in the inlet pylon via quartz fibre bundles. The telescopes' field of view is $1.9^{\circ}$ with elevation angles of $-82^{\circ}$ (named nadir), $-10^{\circ},+10^{\circ}$ relative to the horizon. They point to the right, perpendicular to the flight direction. The spectrometers are temperature stabilised to minimize changes of the instrumental response during flight. The spectral range for two units is $321-453 \mathrm{~nm}$, with the third one $\left(-10^{\circ}\right)$ having a slightly different spectral range, namely $289-441 \mathrm{~nm}$. The spectral resolution of all three spectrometers is approximately $0.5 \mathrm{~nm}$ full width at half maximum, but depends on the wavelength considered. The temporal resolution is $30 \mathrm{~s}$, corresponding to a horizontal resolution of $\approx 7.5 \mathrm{~km}$. To reduce noise in the spectra obtained, sometimes 10 spectra are co-added resulting in a resolution of $5 \mathrm{~min}$ or $\approx 75 \mathrm{~km}$ respectively. Details on the instrument are given in Dix et al. (2009).

The Multi AXis DOAS (MAX-DOAS) technique uses scattered sunlight and therefore the light path is not well defined. The analysis of the spectra yields slant column densities (SCD) that are are integrated concentrations along an intensity weighted average light path. For comparisons with other observations and models the Vertical Column Density (VCD) is commonly used, which is the vertically integrated concentration, and therefore independent of the light path and the instrument's viewing geometry. The ratio between the observed SCD and the VCD is called air mass factor (AMF) or column weighting function, which depends not only on the viewing direction and the SZA, the cloud cover or the aerosol extinction, but also on the gas vertical profile shape. The actual viewing geometry causes different sensitivities of the individual telescopes for a certain air mass, by which trace gas concentration profiles close to the flight altitude can be retrieved (Bruns et al., 2004). The sensitivity of the measured spectral radiance to a trace gas concentration at certain altitude is commonly known as weighting function (WF). The box air mass factor (box-AMF) is a similar but more intuitive measure for the instruments relative sensitivity for a certain altitude layer. It is defined as the contribution of this layer (or box) to the total observed slant column density relative to the vertical column density in this layer.

The maximum sensitivity for the two near horizontally $\left(-10^{\circ}\right.$ and $\left.+10^{\circ}\right)$ viewing telescopes is reached close to the aircraft's flight level of $11.6 \mathrm{~km}$ (Fig. 1). For the downward $\left(-10^{\circ}\right)$ viewing direction the sensitivity is also high below the flight level, but decreases rapidly with distance below the aircraft, especially when flying above clouds. The cloud extinction coefficient was set to $5 \mathrm{~km}^{-1}$ in this simulation, which results in a cloud optical thickness of 10 , because the total cloud was $2 \mathrm{~km}$ thick. Between the flight altitude and the cloud top level the light path is slightly increased by multiple scattering, leading to an enhanced sensitivity. The decrease in sensitivity with height above the flight altitude is weakest for the upward $\left(+10^{\circ}\right)$ looking 
telescope. For the observation of the Kasatochi plume additional information on the clouds cover (Sect. 3.2) and the aerosols are included (Sect. 4.4, compared to Fig. 1 the AMF is slightly enhanced $(\sim 2 \%)$. Above a certain altitude the sensitivity for all viewing directions reaches the stratospheric approximation $1 / \cos (\mathrm{SZA})$ depending solely on the solar zenith angle (SZA). During the period of the $\mathrm{SO}_{2}$ observation the solar zenith angle changed only from $76.4^{\circ}$ to $73.2^{\circ}$, therefore the respective change in the AMF can be neglected. Because of the complexity of the contributing light paths, they are simulated by means of a radiative transfer model. The radiative transfer program used, McArtim (Monte Carlo Atmospheric Radiative Transfer and Inversion Model) (Deutschmann, 2009), is a full spherical Monte Carlo based algorithm to approximate the path of individual photons through the earth atmosphere. The interaction of the sunlight with the atmosphere including scattering at aerosols or molecules as well ground reflection is estimated from the different photon paths. The model was validated by a comparison with other radiative transfer models as described in Wagner et al. (2007).

As the $\mathrm{O}_{4}$ vertical column in the atmosphere is relatively constant (small changes due to different pressure and temperature profiles can be neglected) all changes in the observed $\mathrm{O}_{4}$ column density are caused by changes in the atmospheric light path. Therefore $\mathrm{O}_{4}$ observations are often used as proxy to estimate cloud properties (Wagner et al., 2004; Heue, 2005). Sometimes additional information on the aerosol optical thickness based on MODIS (http://ladsweb.nascom.nasa. gov, May 2009), Calipso (http://www-calipso.larc.nasa.gov, May 2009) or Aeronet Data (http://aeronet.gsfc.nasa.gov/, May 2009) is used to estimate the cloud and aerosol properties as input of the radiative transfer simulations.

Although most of the ultraviolet radiance at wavelengths less than $320 \mathrm{~nm}$ is absorbed by stratospheric ozone, the analysis relies on the weak signals above $312 \mathrm{~nm}$, as the strongest differential $\mathrm{SO}_{2}$ absorption does occur in the UV range between 295 and $306 \mathrm{~nm}$, and decreases fast towards longer wavelengths (Bogumil et al., 2003). Consequently the $\mathrm{SO}_{2}$ sensitivity of the DOAS retrieval in the wavelength interval $321.65-345 \mathrm{~nm}$ is rather low, for the spectra recorded with the two spectrometers connected to the $+10^{\circ}$ and $-82^{\circ}$ telescopes. Only with the $-10^{\circ}$ viewing direction can a high sensitivity for $\mathrm{SO}_{2}$ be achieved by using the wavelength interval between 312 and $330 \mathrm{~nm}$. For $\mathrm{SO}_{2}$ the same cross section $(273 \mathrm{~K})$ as for the GOME-2 data retrieval (Sect. 2.4) was used; by which the systematic error in the comparison caused by different $\mathrm{SO}_{2}$ cross sections is excluded. On the other hand, the $\mathrm{SO}_{2}$ column is overestimated by both CARIBIC and GOME- 2 as the temperature at the plumes altitude was about $-50^{\circ} \mathrm{C}$, compared to a more realistic temperature the cross section and hence the total column deviate by $\approx 6 \%$.

Moreover, the absorption cross sections of $\mathrm{O}_{3}$ (two different cross sections for $223 \mathrm{~K}$ and $243 \mathrm{~K}$ ), $\mathrm{NO}_{2}, \mathrm{BrO}, \mathrm{HCHO}$, and for the longer wavelength ranges $(336-367 \mathrm{~nm}) \mathrm{O}_{4}$, were
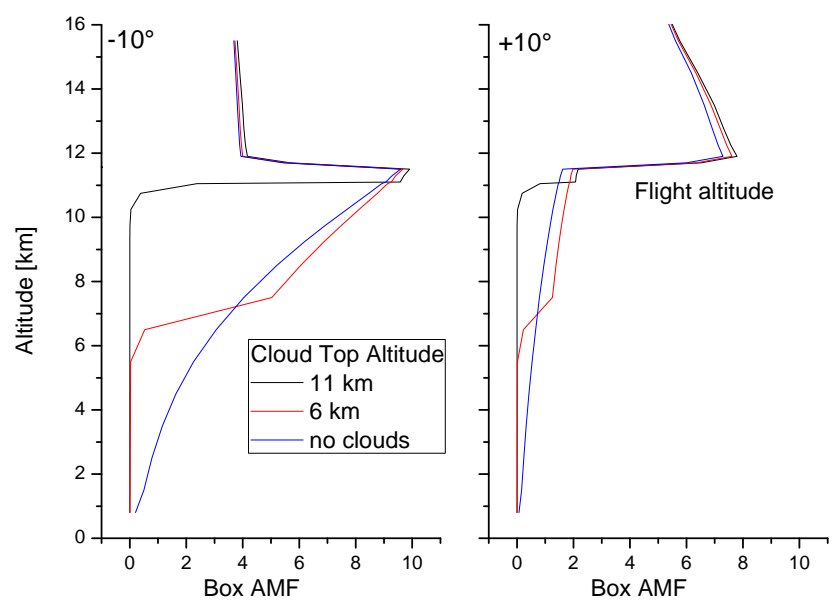

Fig. 1. $\mathrm{SO}_{2}$ Box-AMF (320nm) for the CARIBIC DOAS instrument for two different cloud top altitudes 11 and $6 \mathrm{~km}$ and cloud free conditions. A typical flight altitude for the CARIBIC Airbus of $11.6 \mathrm{~km}$ was assumed for the calculation. Close to the cloud top the sensitivity is slightly enhanced due the high reflectivity of the cloud. The cloud's extinction coefficient was set to $5 \mathrm{~km}^{-1}$, therefore the sensitivity decreases rapidly, and is close to zero below the cloud. In order to focus on the influence of the cloud top altitude, no aerosols are included in this simulation.

included in the DOAS fit. The filling-in of the Fraunhofer lines caused by inelastic scattering of light (Grainer and Ring, 1962) was corrected by including a Ring spectrum (Bussemer, 1993; Kraus, 2006) in the retrieval. The Ring spectrum is calculated from the reference spectrum. A third order polynomial was applied to consider the broad band absorption and scattering effects. A reference spectrum is included to account for the strong Fraunhofer lines; thereby the reference SCD is subtracted. If the SCD of the selected reference is higher than an observation, the differential SCD (dSCD) will be negative (e.g. $\mathrm{O}_{4}$ in Fig. 4). For the volcanic $\mathrm{SO}_{2}$ plume, we chose a reference spectrum close to the plume at 05:00 UTC (Fig. 4). As the reference SCD is unknown it might add an offset to the time series, and thereby affect the intercept of the comparison with GOME-2 data (Sect. 4.5, Fig. 14). The noise in the background SCDs is $\pm 6.5 \times 10^{15} \mathrm{molec} / \mathrm{cm}^{2}$, as illustrated in Figs. 4 and 7. Figure 2 shows an example fit of the $\mathrm{SO}_{2}$ retrieval for the 10 spectra average between 05:43:32 and 05:48:37 UTC.

Consequently a wavelength $(360 \mathrm{~nm})$ in the $336-367$ interval was used to estimate the cloud optical thickness, based on the $\mathrm{O}_{4}$ observations and the intensity at $360 \mathrm{~nm}$ and $380 \mathrm{~nm}$. Additional details on the volcanic aerosols above the cloud (Sect. 4.4 and Fig. 14) are retrieved from the intensity ratios between reference (cloud free) and the plume observations for two small wavelength intervals (around $320 \mathrm{~nm}$ and $360 \mathrm{~nm}$ ). The simulations for $\mathrm{O}_{4}$ and the instensity ratios however can not be performed independent from one another. 


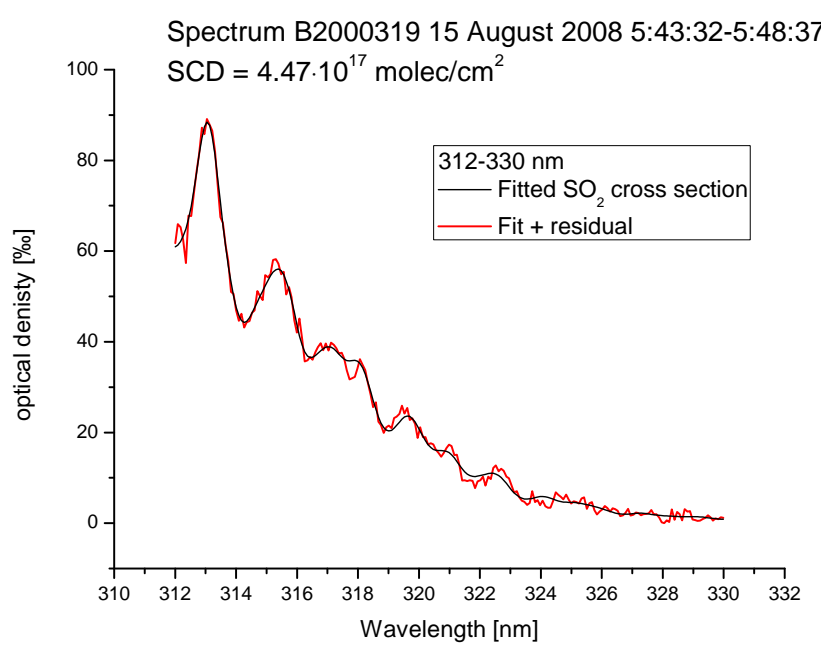

Fig. 2. Example fit for $\mathrm{SO}_{2}$, (sum of 10 spectra) recorded between 05:43:32 and 05:48:37 UTC while flying over the Kasatochi plume.

The results for the cloud optical thickness and aerosol optical thickness are then included in the radiative transfer simulation for the $\mathrm{SO}_{2} \mathrm{AMF}$ at $320 \mathrm{~nm}$.

\subsection{Wind measurements and the trajectory model}

The aircraft's position and also the roll and pitch angle as well as relevant meteorological observations are provided by the aircraft's standard ARINC system and are logged in flight by the master computer in the container. Temperature and pressure are measured directly and the true airspeed is based on measurements with Pitot tubes. The wind velocity is calculated from the vector difference between the aircraft's true air speed and the speed over ground based on an inertial navigation system or on the GPS coordinates. Details on the methodology of the airborne wind speed measurements are given e.g. in Khelif et al. (1999).

The time stamp of the ARINC data is stored with the other data on the CARIBIC master PC, and from this the deviation of the master clock can be calculated. In fact the typical time shift during four flights in three days is of the order of a few seconds. This is important as all instruments are synchronised to the master PC.

In addition to the large suite of measurements, the CARIBIC data are complemented with information based on meteorological analyses made with the ECMWF (European Centre for Medium range Weather Forecasts) global weather forecast model. The trajectory model TRAJKS (Scheele et al., 1996; Stohl et al., 2001) of KNMI was used to calculate two day forward as well as eight day backward 3-D trajectories for every $3 \mathrm{~min}$ along the flight path. The trajectory model uses archived ECMWF analysis data at a horizontal resolution of $1^{\circ} \times 1^{\circ}$ and at 90 vertical levels. Various meteorological parameters, such as potential vorticity (PV), are calculated from the archived ECMWF analysis data and in- terpolated in space and time to the location of the CARIBIC aircraft as part of the post-flight analysis.

\subsection{GOME-2 on MetOp-A}

The GOME-2 (Global Ozone Monitoring Experiment) on MetOp-A is the first of a series of three identical instruments. With this series the successful long term observations of atmospheric trace gases by GOME and SCIAMACHY will be extended until 2020. MetOp-A was launched into a sun-synchronous polar orbit at $800 \mathrm{~km}$ altitude in October 2006 and crosses the equator at 09:30 LT (local time). The GOME-2 instrument is a 4 channel UV/Vis grating spectrometer, which covers the wavelength region of 240 $790 \mathrm{~nm}$ with a spectral resolution of $0.2-0.4 \mathrm{~nm}$. Besides the backscattered and reflected radiance from the earth it also observes direct sunlight. The ground pixel size is $80 \times 40 \mathrm{~km}^{2}$ and the total swath width is $1920 \mathrm{~km}$, thereby achieving daily coverage of the mid latitudes (http://www. esa.int/esaLP/LPmetop.html, September 2009).

The $\mathrm{SO}_{2}$ absorption is analysed from the satellite spectra in the wavelength range from $312-324 \mathrm{~nm}$ using the DOAS method. To remove the Fraunhofer lines, a direct sun spectrum (containing no atmospheric absorptions) is included in the fitting process. The trace gas cross sections for $\mathrm{O}_{3}$ (221 K; Gür et al., 2005), SO 2 (273 K; Bogumil et al., 1999), a Ring spectrum (Bussemer, 1993; Wagner et al., 2009) and an inverse spectrum (both calculated from the direct sun spectrum) are included in the spectral analysis. Also a polynomial of degree 4 is included to account for broad band effects and atmospheric scattering. Since the atmospheric light paths within the selected fitting window change systematically with wavelength (e.g. van Roozendael et al., 2006), not only the original ozone absorption cross section but also a second one (the original cross section scaled with the a fourth order polynomial in wavelength) are included in the fitting algorithm. It should be noted that in principle additional ozone absorption cross sections for other temperatures might be included in the fitting algorithm. However, for the selected case study, no significant change of the retrieved $\mathrm{SO}_{2}$ results and the magnitude of the residual was found, if additional temperatures were considered. Another systematic error source is the potential saturation effects of the measured $\mathrm{SO}_{2}$ absorption. It was shown by Richter et al. (2009) and Yang et al. (2009) that for very high atmospheric $\mathrm{SO}_{2}$ loads the retrieved $\mathrm{SO}_{2}$ optical depth is no longer a linear function of the atmospheric $\mathrm{SO}_{2} \mathrm{SCD}$. In such cases this nonlinearity has to be corrected for, or alternatively, the analysis has to be performed at wavelengths with much weaker values of the $\mathrm{SO}_{2}$ absorption cross section. However, the $\mathrm{SO}_{2}$ absorptions investigated in this study $(\mathrm{OD} \leq 5 \%)$ are far below the threshold at which saturation becomes an important effect. To convert the $\mathrm{SO}_{2} \mathrm{SCD}$ to VCD the geometrical AMF is applied: $\mathrm{AMF}=1 / \cos (\mathrm{LOS})+1 / \cos (\mathrm{SZA})$ where LOS and SZA are the line of sight $\left(\right.$ nadir $=0^{\circ}$ ) and the solar 
zenith angle, respectively. During the plume observation the SZA was $\approx 44^{\circ}$, hence the geometrical AMF varied between 2.4 (nadir) and $2.8\left( \pm 45^{\circ}\right)$ Only for the direct comparison to the CARIBIC DOAS observation (Figs. 15 and 14), radiative transfer simulations (Deutschmann, 2009) were performed including the same cloud and aerosol settings as for CARIBIC DOAS.

\section{Observations}

\subsection{GOME-2 $\mathrm{SO}_{2}$ distribution patterns}

After the Kasatochi volcano on the Aleutian Islands, Alaska had erupted on 7 August 2008, part of the plume was transported to central Europe within a week. The distribution and dispersion of the $\mathrm{SO}_{2}$ plume was observed by various satellite instruments e.g. OMI (http://www.temis.nl/aviation/so2. php, September 2009 or http://satepsanone.nesdis.noaa.gov/ pub/OMI/OMISO2, March 2010). Theys et al. (2009) also detected enhanced $\mathrm{BrO}$ columns close to the source region using the GOME-2 instrument.

In Fig. 3 the vertical column densities based on the GOME-2 spectra are shown. Although the centre of the plume is still over eastern Canada reaching out to Greenland, an eastern edge of the volcanic cloud has reached Western Europe stretching from Western Mediterranean to the Baltic sea. This particular sub-plume was also observed during the CARIBIC measurement flight 247 (15 August 2008), and is investigated here.

\subsection{CARIBIC-DOAS observations of the Kasatochi plume}

The Lufthansa Airbus equipped with the CARIBIC container returned from Chennai (India) 15 August 2008 and crossed the plume from 05:10 to 05:50 UTC, just before descending to Frankfurt airport. The plume was apparent in the observations as an enhanced aerosol number density (Fig. 7) and increases in the carbon and sulphur mass concentrations of the aerosol (Martinsson et al., 2009). The $\mathrm{SO}_{2}$ time series for the $-10^{\circ}$ telescope (lower part of Fig. 4) shows two significant peaks; the first one between 05:10 and 05:25 UTC and a second one between 05:38 and 05:48, when the SCD decreased rapidly. Although the data of the upwards looking telescope $\left(+10^{\circ}\right)$ are very noisy an enhanced SCD at 05:48 can be observed there as well.

For a quantitative interpretation of the observed $\mathrm{SO}_{2}$ time series, additional DOAS and other CARIBIC measurements are to be taken into account. The $\mathrm{O}_{4}$ column densities (Fig. 4, right panels) show a major drop during the first $\mathrm{SO}_{2}$ peak and decrease even further just before the second peak. This strong decrease is caused by a cloud below the flight altitude, which shields the lower and denser atmosphere. Later on, the $\mathrm{O}_{4}$ signal increases again, at the moment that the aeroplane descended into the cloud. The video camera in

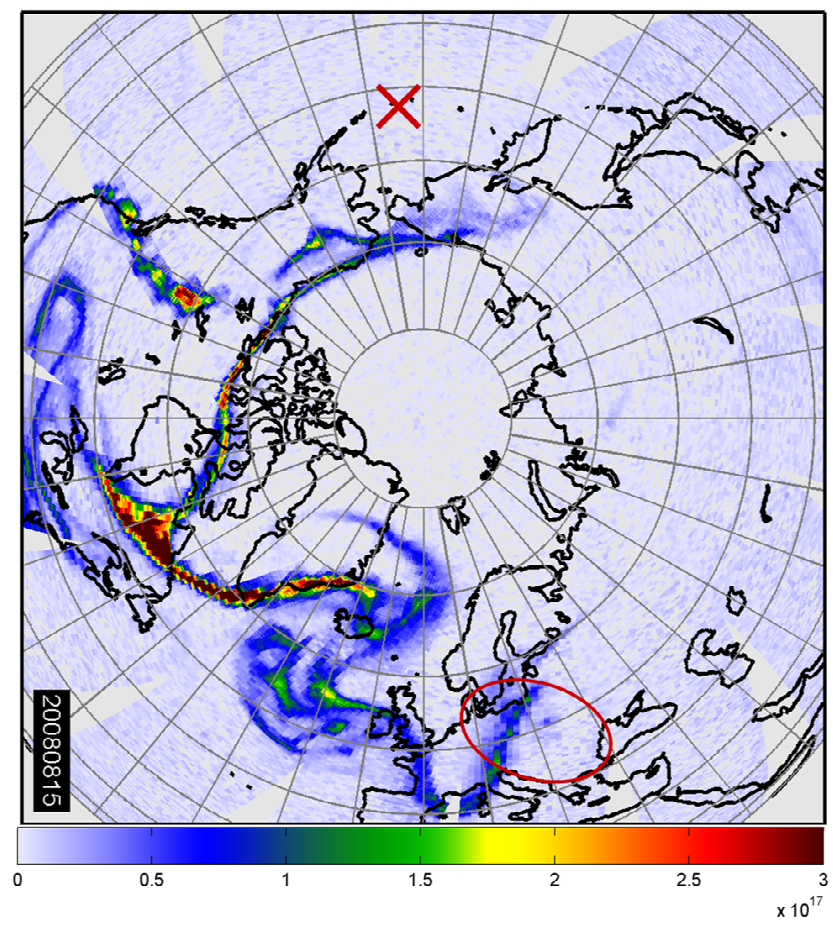

Fig. 3. Distribution of the Kasatochi $\mathrm{SO}_{2}$ plume (mostly north of $40^{\circ}$ ) one week after the eruption (15 August 2008) based on GOME-2 VCD, the colour scale ranges from 0 to $3 \times 10^{17} \mathrm{molec} / \mathrm{cm}^{2}$. The cross indicates the position of the Kasatochi volcano (Aleutian Islands, Alaska, $52.17^{\circ} \mathrm{N}$, $\left.175.51^{\circ} \mathrm{W}\right)$. The part of the plume discussed in the paper is indicated by the red ellipse.

the inlet pylon confirms the cloud cover below the aeroplane (Fig. 5). At the beginning (first $\mathrm{SO}_{2}$ peak) the cloud is optically thin therefore the $\mathrm{O}_{4}$ slant column is reduced by only $1.7 \times 10^{43} \mathrm{molec}^{2} / \mathrm{cm}^{5}$. Later on, the cloud is denser and the column density decreases further, until the aircraft dives through the cloud. According to the rapid increase in the observed cloud liquid water (Fig. 7) the cloud top altitude is at $11000 \mathrm{~m} \pm 100 \mathrm{~m}$.

The high cloud top hight is in agreement with the Meteosat cloud analysis product (05:45 UTC, http://www.eumetsat.int/ Home/index.htm, April 2010), specifying the cloud as Cirrus cloud. Only close to Frankfurt also Alto stratus and Cumulonimbus clouds were observed, which indicates that there were several layers of clouds in this specific region. For both DOAS and GOME-2 the highest cloud layer is of mayor interest, especially as the $\mathrm{SO}_{2}$ layer was above this cloud. The cloud base height close to Frankfurt was about $6 \mathrm{~km}$, based on the cloud water content, however according to the Meteosat analysis, the cloud cover was not homogeneous, therefore the cloud base level for the clouds below the plane is still unknown.sat analysis, the cloud cover was not homogeneous, therefore the cloud base level for the clouds below the plane is still unknown. Therefore the cloud base was fixed to 


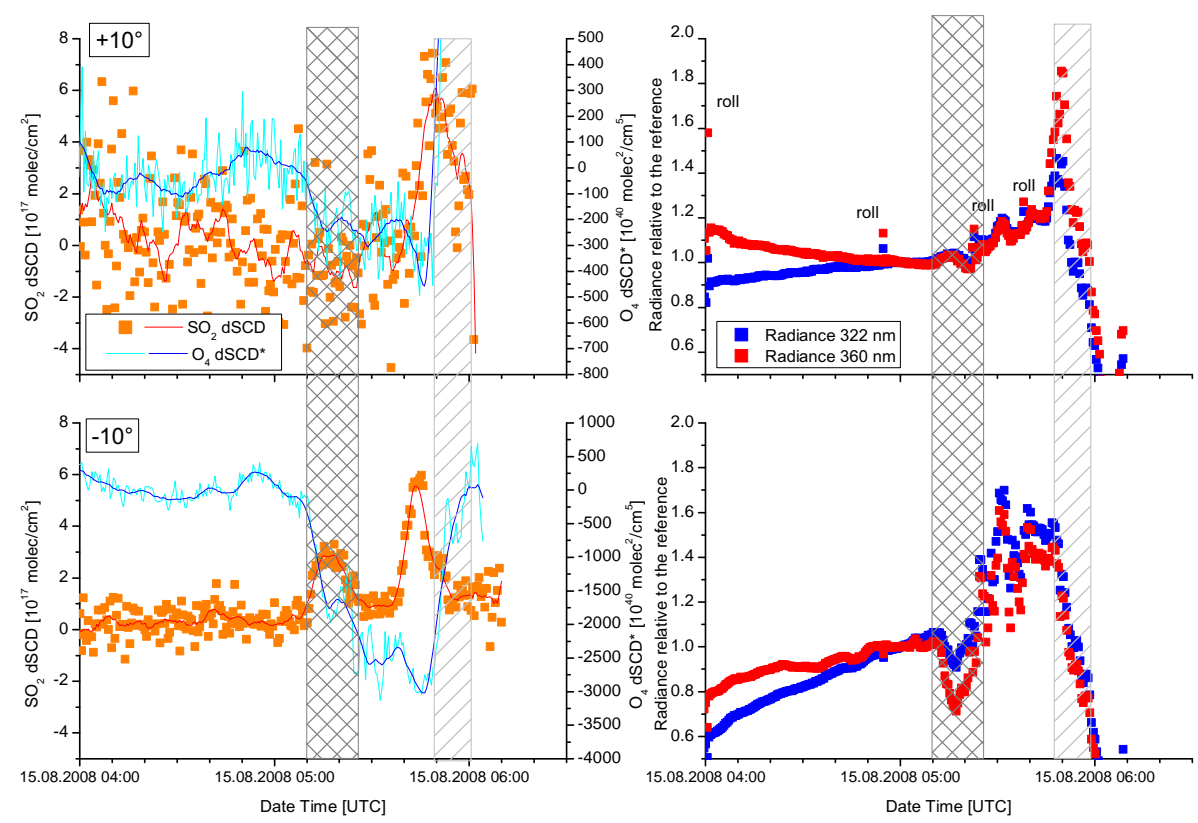

Fig. 4. left: Time series of $\mathrm{SO}_{2}$ and $\mathrm{O}_{4} \mathrm{dSCDs}$ for the two viewing directions $-10^{\circ}$ (bottom) and $+10^{\circ}$ (top). Due to the limited spectral range of the detector the $+10^{\circ}$ retrieval is very noisy and the detection limit is rather high, however, around 05:48 an enhanced dSCD is also observed. Right: Relative intensity for the wavelength $320 \mathrm{~nm}$ and $360 \mathrm{~nm}$, normalised to the reference (05:00 UTC). During the first $\mathrm{SO}_{2}$ peak the intensity of the downward looking instrument is reduced by the cloud (cross hashed); the opposite effect is found for the upward telescope. The dive through the cloud is marked by the hashed area. Some intensity data points seem to be outliers, but can easily be explained by the roll angle of the plane, when the telescope is directed to the cloud.

$9 \mathrm{~km}$ and the droplets' single scattering albedo was also kept constant at $\omega=0.99$ and only the Cloud Optical Thickness (COT) was varied in the radiative transfer simulation. For cloud droplets a SSA of 0.99 is rather low, but there might be part of the carbonous containing aerosols (Martinsson et al., 2009) from the volcano in the cloud.

For 7 different COT values between 0.6 and 16 the $\mathrm{O}_{4}$ SCDs (Fig. 6) and intensities were calculated. The $\mathrm{O}_{4} \mathrm{SCDs}$ at $360 \mathrm{~nm}$ and around $380 \mathrm{~nm}$ (not shown) were considered for the cloud retrieval. The influence of the aerosol layer above the cloud on the $\mathrm{O}_{4} \mathrm{SCD}$ was found to be small and is therefore neglected here. The retrieval of aerosol extinction and single scattering albedo (Sect. 4.4) is mainly based on the intensity ratios relative to the reference. However, the influence of aerosols and clouds can not be treated completely independent. As a result we retrieved a rather low optical density of 0.8 for the first peak and a dense cloud with an optical density of 10 at 05:44.

The MODIS overpass time was at 10:02 UTC and hence $\approx 04: 30 \mathrm{~h}$ later than the CARIBIC observations, making a direct comparison here even more challenging than for GOME-2. The reduced intensity we observed during the first peak (Fig. 4) could not be modelled considering a bright cloud only. However if dark aerosols above the clouds are taken into account (Sect. 4.4) a slight decrease can be simulated.
The sensitivity to local $\mathrm{SO}_{2}$ concentrations at flight altitude is enhanced by the cloud (Fig. 1). The AMF for the altitude range between 11 and $12 \mathrm{~km}$ increased from 7.9 for a clear sky approximation to 8.29 if the cloud top height is assumed to be at $11 \mathrm{~km}$. This increase of less than 5\%, however, is not sufficient to explain the observed peaks, especially as no aerosols were included in the simulation. In fact, if aerosols above the clouds are considered (Sect. 4.4) the AMF is slightly reduced despite the presence of the bright cloud. The change in the AMF for the two different clouds is less than $1 \%$, therefore the difference in $\mathrm{SO}_{2}$ peak heights $\left(2.9\right.$ and $\left.5.9 \times 10^{16} \mathrm{molec} / \mathrm{cm}^{2}\right)$ can only be explained by different $\mathrm{SO}_{2}$ columns.

Additional observations and flight parameters are given in Fig. 7. Many variables were changing during the observation of the second $\mathrm{SO}_{2}$ plume, particularly while the aircraft started its descent at 05:44. Only minutes later PV (modelled) and ozone concentration rapidly dropped from 4 to $0 \mathrm{PVU}$ and from 150 to $75 \mathrm{ppb}$ respectively, witnessing the re-entry into the troposphere. Just when the $\mathrm{SO}_{2} \mathrm{SCD}$ suddenly decreased by a factor of 2 , cloud water appeared in a matter of seconds. This shows that the plane entered the cloud layer it had been passing over. The shorter light path through the $\mathrm{SO}_{2}$ plume, which is mainly situated above the cloud reduces the $\mathrm{SO}_{2}$ signal. Another reason for the sharp decline in the observed $\mathrm{SO}_{2}$ column might be a locally 


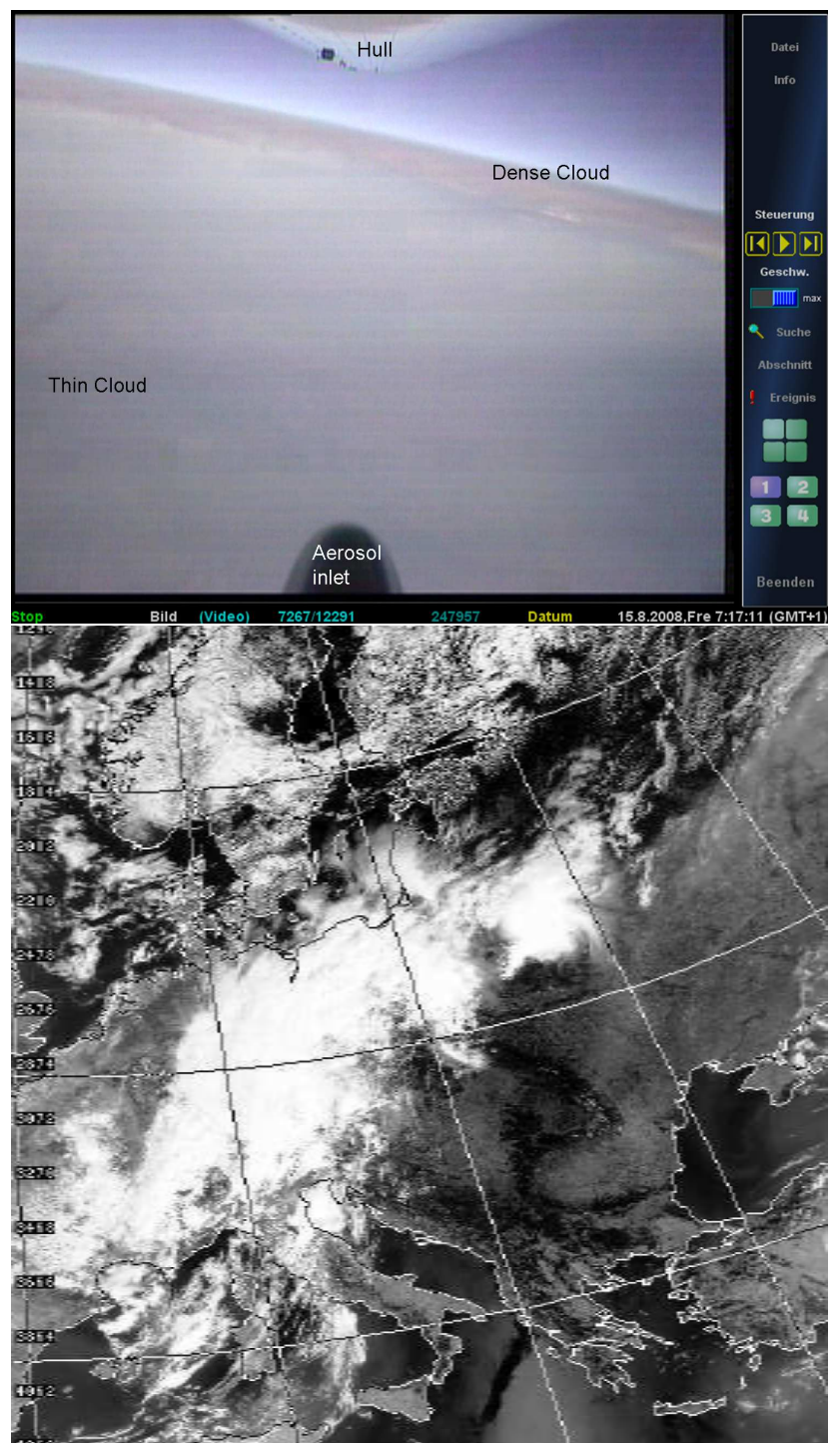

Fig. 5. Top: Picture of the cloud cover at 05:17 UTC (the time shown is local time in Frankfurt). Like the pylon the camera is tilted by $8^{\circ}$. At this time the centre of the minor maximum was observed. The clouds seem to be thin but high. The large cloud close to the horizon is at $11 \mathrm{~km}$ altitude.

Bottom: Cloud cover over Europe at 09:07 UTC from NOAA 17 (Dundee Satellite Receiving Station: http://www.sat.dundee.ac.uk/, March 2010.)

reduced $\mathrm{SO}_{2}$ concentration due to scavenging by the cloud droplets (e.g. Lohmann et al., 2001).

During the descent, the second peak in the $\mathrm{SO}_{2}$ column was first observed through the $-10^{\circ}$ telescope and subsequently by the upward looking one (Fig. 4). This suggests a thin $\mathrm{SO}_{2}$ layer situated just above the cloud. Due to the low data quality of the $+10^{\circ}$ a more accurate retrieval (e.g. Bruns et al., 2004) of the $\mathrm{SO}_{2}$ layer is not possible.

Also, the fact that the first peak was not observed by the $+10^{\circ}$ instrument suggests that the $\mathrm{SO}_{2}$ did not reach high
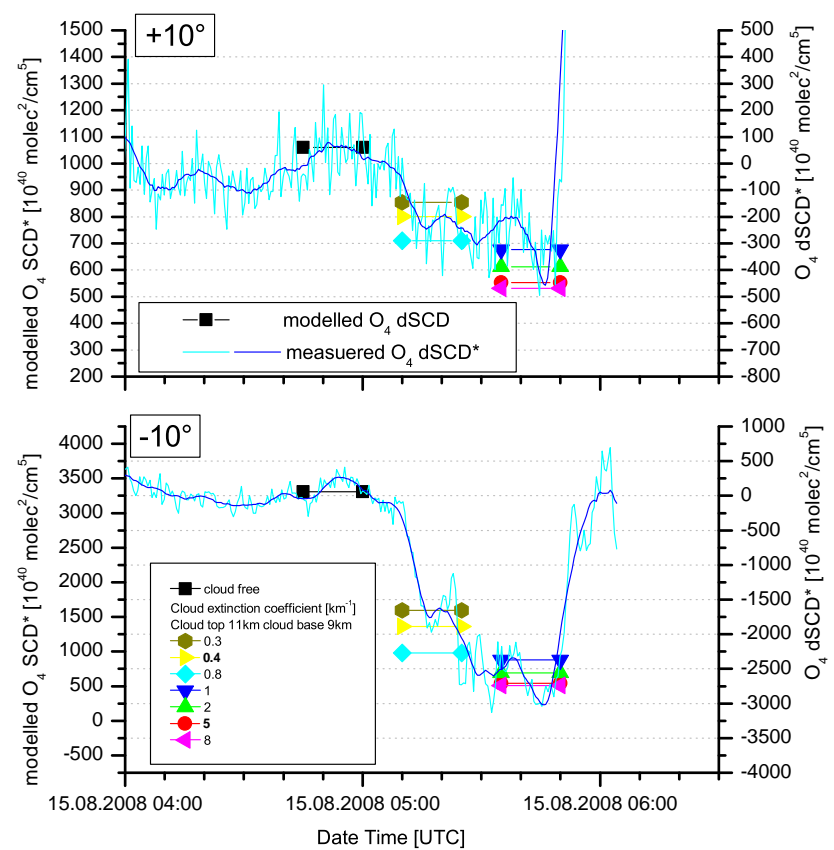

Fig. 6. Observed (Fig. 4) and modelled $\mathrm{O}_{4}$ column densities using the same scale range $\Delta=1300$ and $5000 \times 10^{40} \mathrm{molec}^{2} / \mathrm{cm}^{5}$ for the upward and downward directed telescope respectively. The best agreement between measurement and simulations is obtained for a total cloud optical thickness of $0.8\left(k=0.4 \mathrm{~km}^{-1}\right)$ for the first cloud and $10\left(k=5 \mathrm{~km}^{-1}\right)$ for the second cloud.

above the flight altitude. Nevertheless as the aerosol number concentration is enhanced while the plane is still at $11.6 \mathrm{~km}$ flight altitude, at least part of the plume reaches up to here. In the following we assume the plume altitude to be between 11 and $12 \mathrm{~km}$. Aerosol observations from the CALIPSO satellite instrument also showed an enhanced aerosol number density above the cloud reaching up to about $\approx 12 \mathrm{~km}$, but not significantly higher than that. As both aerosols and $\mathrm{SO}_{2}$ originated from the same source, it seems justified to assume that the $\mathrm{SO}_{2}$ layer also does not extent to altitudes above $12 \mathrm{~km}$. To illustrate the effect of a varying plume thickness, several box profiles, resulting in the same SCD, are depicted in Fig. 8. A simple inversion algorithm based on the box-AMF (Fig. 1) was applied to the maximum of the observed slant column densities $\left(5.9 \times 10^{17} \mathrm{molec} / \mathrm{cm}^{2}\right)$. From this the volume mixing ratios (Fig. 8) for different $\mathrm{SO}_{2}$ layers were retrieved. As a consequence of the varying plume thickness the vertical column density would also vary between $1 \times 10^{17} \mathrm{molec} / \mathrm{cm}^{2}$ and $7 \times 10^{16} \mathrm{molec} / \mathrm{cm}^{2}$.

In accordance with the previous discussion on the plume's altitude, the altitude range between 11 and $12 \mathrm{~km}$ seems to be most realistic. As no aerosols above the cloud are included in these calculations, the AMFs and the mixing ratios shown here are slightly different $(+8 \%)$ from those used for the comparison with GOME-2. 
Flight \#247 Chennai -> Frankfurt, August 14-15, 2008
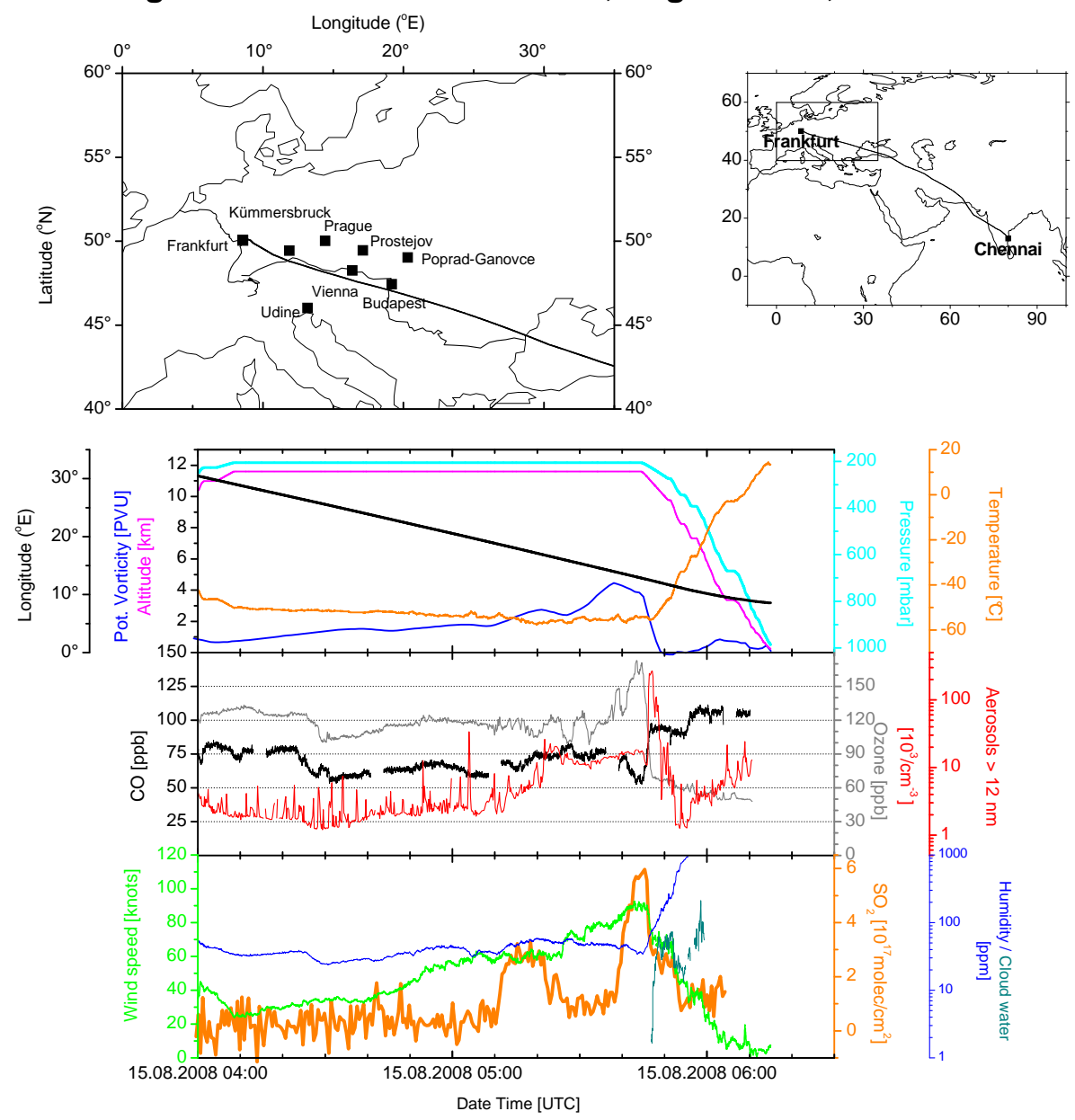

Fig. 7. Overview of the CARIBIC flight track and selected measurements from 04:00 to 06:30 UTC 15 August 2008. Along the flight track some sounding stations are depicted. The second panel gives measured flight information, and PV (model based). $\mathrm{Both}^{\mathrm{SO}} \mathrm{O}_{2}$ peaks (bottom) occur at $\mathrm{PV} \geq 2$. The rapid decline in the $\mathrm{SO}_{2} \mathrm{SCD}$ (second peak) coincides exactly with an increase in cloud water and aerosol.

\section{Comparison of CARIBIC and GOME-2}

For a detailed comparison with the GOME-2 observations the temporal mismatch between the two observations has to be considered. The CARIBIC measurements of the Kasatochi plume were taken at 05:30 UTC $\pm 15 \mathrm{~min}$, whereas MetOp-A/GOME-2 passed-over at 08:50 UTC i.e. $3 \mathrm{~h}$ and $20 \mathrm{~min}$ after the Lufthansa Airbus. Since both time signals (master PC and ARINC) agreed with a difference of $6 \mathrm{~s}(1 / 5$ of the DOAS integration time), the CARIBIC overpass is accurately timed. The plume altitude is an important parameter for the trajectory calculations as the wind field changes strongly with altitude. A first comparison without any trajectory calculation is shown in Fig. 9. The higher maximum (second CARIBIC $\mathrm{SO}_{2}$ plume) coincides very well with the plume as observed by GOME-2, but for the lower one $\left(17^{\circ} \mathrm{E}\right)$ the only similar $\mathrm{SO}_{2} \mathrm{VCD}$ pattern is observed about $3^{\circ} \mathrm{N}$ (NE) of the aeroplane's flight track.

\subsection{Time correction}

As a first approach we use $4 \mathrm{~h}$ forward trajectories calculated with TRAJKS to estimate the plume's position at 08:50 UTC. While the main peak of the CARIBIC DOAS measurements is correctly shifted along the Kasatochi plume, the minor peak is still off from the next local $\mathrm{SO}_{2}$ maximum observed by GOME-2 (Fig. 10 top). The distance is of the order of two GOME-2 pixels i.e. $\approx 80 \mathrm{~km}$. In the lower part of Fig. 10 the cross section along the shifted flight track is illustrated. The GOME-2 VCD of the nearest pixel is shown for each individual CARIBIC observation creating the step-function for the GOME-2 data. At the position of the smaller maximum no evidence for enhanced $\mathrm{SO}_{2}$ columns is observed by GOME-2.

Similar discrepancies are found when using the HYSPLIT trajectory model at different altitudes $(10-13 \mathrm{~km})$ or the wind speeds and directions, actually measured on board of the CARIBIC Airbus (assuming these to remain constant along 


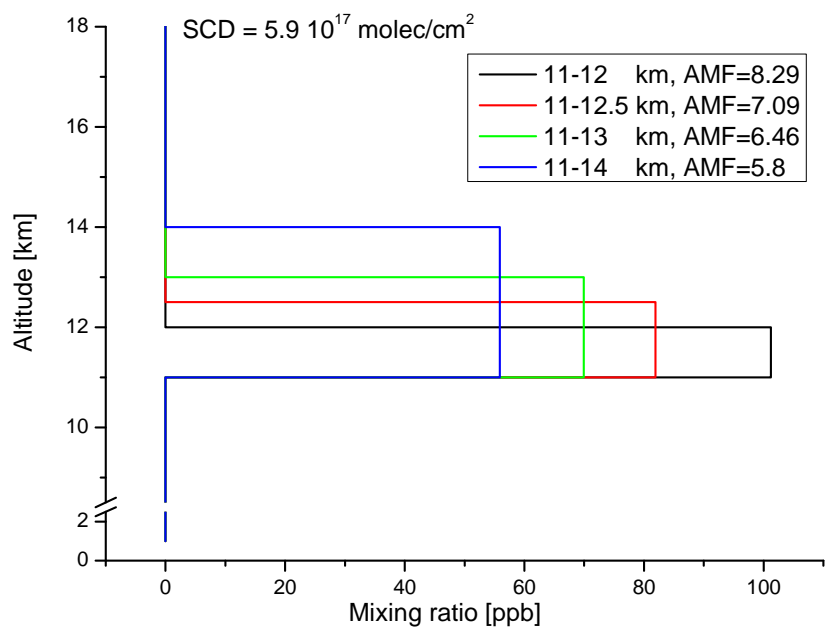

Fig. 8. $\mathrm{SO}_{2}$ box profiles, that lead to the observed $\mathrm{SCD}$ of $5.9 \times 10^{17} \mathrm{molec} / \mathrm{cm}^{2}$. The black line illustrates a profile from 11 to $12 \mathrm{~km}$, red reaches 11 to $12.5 \mathrm{~km}$, green between 11 and $13 \mathrm{~km}$ and in blue from 11 to $14 \mathrm{~km}$. Depending on the plume thickness, the total AMF varies between 8.3 and 5.8. Again no aerosols above the clouds are included in the simulations.

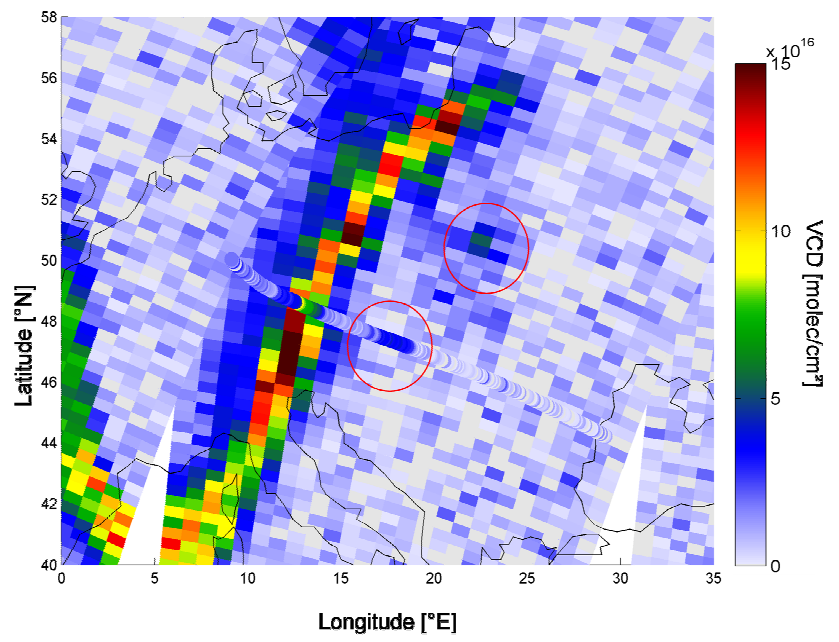

Fig. 9. GOME-2 and CARIBIC DOAS $\mathrm{SO}_{2}$ vertical column density. No time correction is applied.

the trajectories for the subsequent 3 to $4 \mathrm{~h}$; not shown). Also a change in the plume's altitude, which is rather unlikely as the CARIBIC observations demonstrate, does not reduce the distance between the maxima observed by GOME-2 and CARIBIC. The wind speed at $11-12 \mathrm{~km}$ altitude based on observation and models is apparently insufficient for the two maxima to match. However, the wind speeds measured by radio soundings (http://weather.uwyo.edu/upperair/sounding. html, May 2009) agree quite well with the CARIBIC data (Fig. 11). In order to compare the wind speeds for similar air masses, the positions of the soundings stations (Fig. 7) were shifted along the wind field.
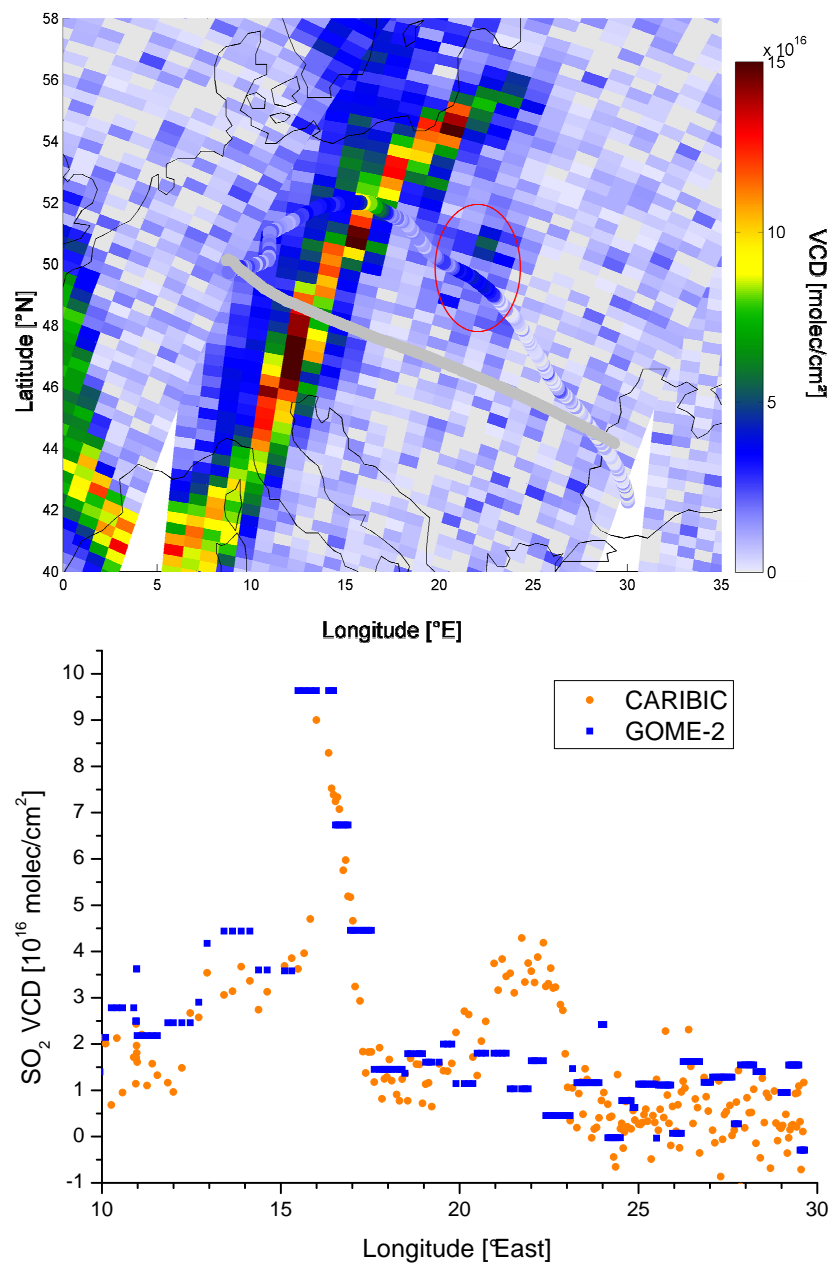

Fig. 10. Similar to Fig. 9 but the CARIBIC $\mathrm{SO}_{2}$ data are shifted relative to the flight track (grey line) using forward TRAJKS trajectories. Bottom: Cross section along the shifted aeroplane path. For each CARIBIC observation the VCD of the nearest GOME-2 pixel is given. No enhancement in the GOME-2 data is observed around the shifted minor peak of the DOAS data.

These radio soundings also confirm the estimate on the plume's altitude, as the maximum wind speed was measured between 10 and $13 \mathrm{~km}$ altitude. At Poprad-Ganovce (Slovakia) the maximum wind speed was 64 knots at $13 \mathrm{~km}$ altitude, which is in the range of the CARIBIC observation (Fig. 11).

\subsection{Geometrical effects}

A geometrical effect, i.e. that the plume was not observed at the position of the aeroplane, but further north as the instrument was pointing north-east is possible but not sufficient to explain the discrepancy in observations. The aircraft is at $11.6 \mathrm{~km}$ altitude and hence only $600 \mathrm{~m}$ above the cloud top. The horizontal distance for the $-10^{\circ}$ line of sight is $3.4 \mathrm{~km}$. If the sun was perfectly in line with the line of sight, the 


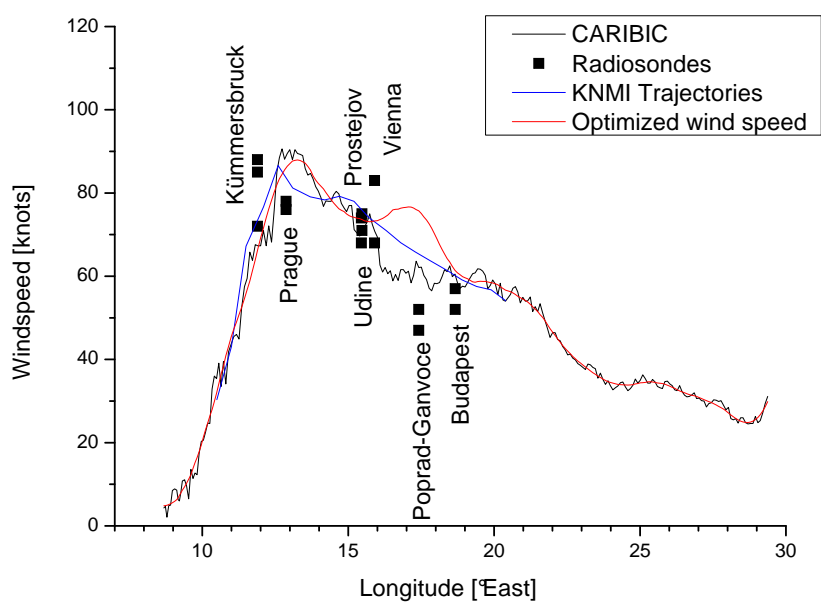

Fig. 11. Wind speed on 15 August 2008 observed by CARIBIC and by radio soundings with a maximum distance to the flight track of $300 \mathrm{~km}$ along the wind direction. In addition the ECMWF winds speed (from the trajectory model output) and the optimized wind speed used for further analysis are shown. Only at Prague and Kümmersbruck soundings were performed at 06:00 UTC, for the other stations both 00:00 and 12:00 UTC are depicted. As the plane was descending to Frankfurt, different measurements for different altitudes are shown in Kümmersbruck. The one closest to the flight altitude fits best, the other two are more related to the plume altitude of $11.5 \pm 0.5 \mathrm{~km}$ but are similar to the CARIBIC data at $11.6 \mathrm{~km}$.

maximum distance would have been $7 \mathrm{~km}$. In fact the sun was $\approx 60^{\circ}$ off from the line of sight. Hence the geometrical effect is at least an order of magnitude too small. If the cloud and the $\mathrm{SO}_{2}$ plume were at lower altitudes, which can not be excluded for the lower maximum, the geometrical shift would increase, but to shift the observations by $20 \mathrm{~km}$ a cloud top height of $8 \mathrm{~km}$ would be necessary. The assumption of such a low but dense cloud with $8 \mathrm{~km}$ top altitude might agree with the $\mathrm{O}_{4}$ slant columns but still contradicts the Meteosat Cloud Product and the video pictures (Fig. 5), where a thin and high cloud can be seen. Moreover the wind speed measured by the soundings was much lower $(\approx 40 \pm 4$ knots $)$ at $6-$ $8 \mathrm{~km}$ altitude compared to the flight level, hence this larger shift caused by the viewing geometry will be outweighed by advection due to the lower wind speed.

\subsection{Enhanced wind speed}

Since the shift in the observation is not caused by the viewing geometry, and we are quite confident concerning the plume altitude, we have to assume that the wind speed might by underestimated by two independent observations (CARIBIC and the radio soundings in Poprad-Ganovce). Or, if the wind speed is correct at the beginning, it might have increased further to the north east instead of having decreased as derived from the trajectory calculations. However, even if the wind speed is not correct at $17^{\circ} \mathrm{E}$, further to the west $\left(15^{\circ} \mathrm{E}\right)$ three soundings (Udine, Vienna and Prostejov) agree quite well with CARIBIC instrument. To reduce the complexity of the trajectory calculations we assume a constant wind speed along the trajectories and use the wind direction observed by CARIBIC. The wind speed is increased between $16.3^{\circ} \mathrm{E}$ and $18^{\circ} \mathrm{E}$, and linearly interpolated to the unchanged values within the neighbouring $0.5^{\circ}$ longitude ranges. Both wind speed and direction were smoothed before calculating the new trajectories. The plume is assumed to stay at $11-12 \mathrm{~km}$ altitude for the next 3-4 h.

A good agreement between the trajectory projected $\mathrm{SO}_{2}$ time series and GOME-2 measurements is found with an $25 \%$ increased wind speed (Fig. 11). The typical error in the ECMWF data is less than $5 \mathrm{~m} / \mathrm{s}$ (Weissmann and Cardinali, 2007) which is about $16 \%$ of the observed wind speed. Higher differences between observed wind speeds and model simulated like the observed ones can occur due to mesoscale meteorolical variability (e.g. filaments or waves) which are not fully resolved by the ECMWF $1^{\circ} \times 1^{\circ}$ resolution.

The overlay of the DOAS data and the GOME-2 data (Fig. 12) shows that both observations match if the CARIBIC data are shifted according to the enhanced wind speed. The sharp increase of the lower maximum $\left(\approx 23.5^{\circ} \mathrm{E}\right)$ is seen by both instruments, also the absolute level of the maximum show good agreement. The local minimum is more pronounced in the CARIBIC data than in the GOME-2. Also the second maximum is observed by both measurements at the same position and with similar amplitude.

The differences observed for the local minimum in the VCD can be reduced if the wind speed in this region is locally increased, but this leads to an inconsistency with some CARIBIC data. If the wind speed is increased here the wind speed at $15.5^{\circ}$ (Vienna or Udine in Fig. 11) would reach the same level as the absolute maximum observed further to the west. This maximum in the wind speed coincides with the observation of stratospheric air masses (high $\mathrm{O}_{3}$ levels and low CO, Fig. 7). Hence, if there was the same wind speed as in the stratospheric air masses, other indicators e.g. $\mathrm{O}_{3}$ and $\mathrm{CO}$ concentrations, would also be expected to show similar values as later on, which is not observed by CARIBIC (Fig. 7).

Extending the extrapolation time to 11:50 UTC which is the OMI-overpass time, shows that the wind field is even more complex; for the smaller peaks do not match neither for the TRAJKS model nor for the enhanced wind speed. While in TRAJKS the wind speed is too low, similar as for GOME2 , the wind speed optimised for the GOME-2 observation however is overestimated for OMI and the assumption of a constant wind direction is no longer valid. Also the position of the main plume is shifted too much to the east with both these wind fields (Fig. 13). 

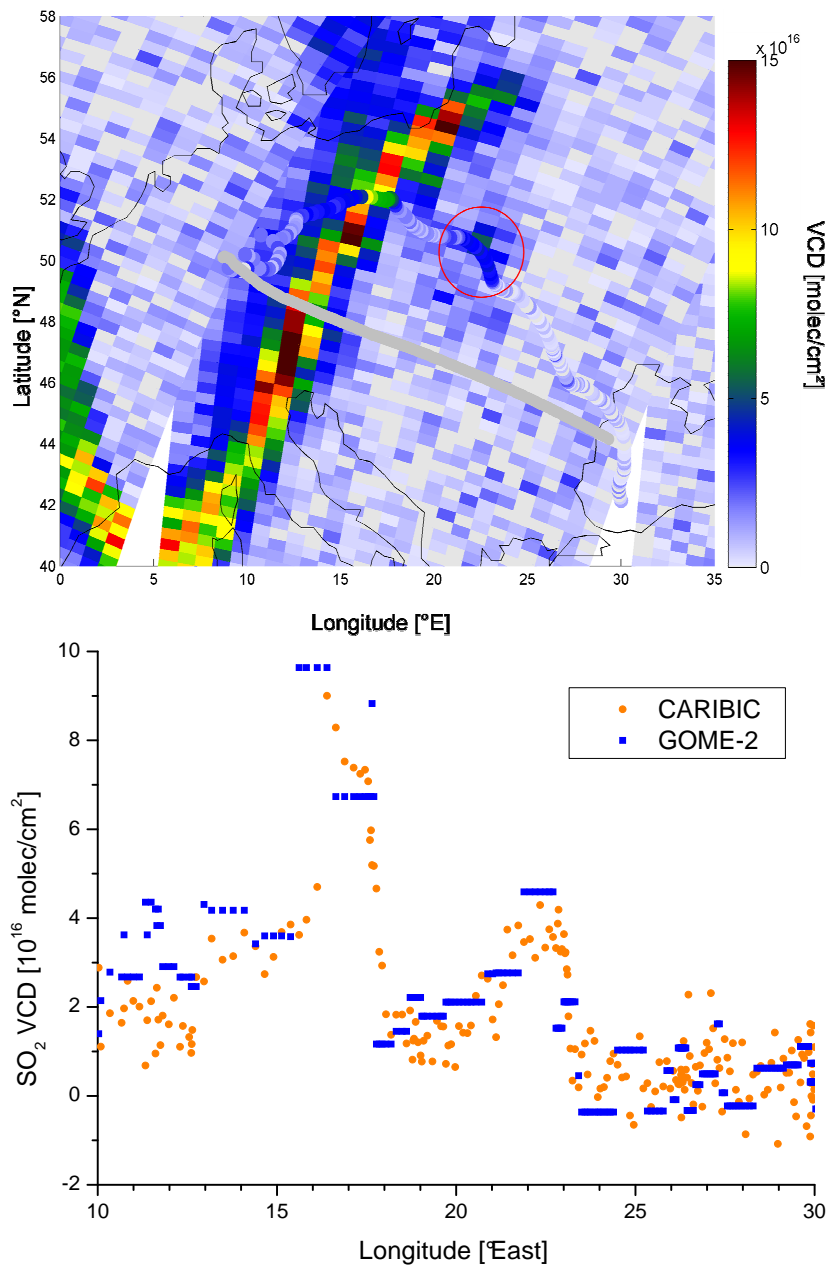

Fig. 12. Similar to Fig. 10 but the CARIBIC $\mathrm{SO}_{2}$ data are shifted relative to the flight track (grey line) using an optimized wind speed. Compared to Fig. 10 the position of the first maximum (bottom) agrees much better.

\subsection{Aerosol properties and air mass factors}

For ground based observations $\mathrm{O}_{4}$ column densities can be used to retrieve aerosol extinction properties (Wagner et al., 2004; Frieß et al., 2006; Irie et al., 2008). However in the current geometry this is not possible, because the aeroplane cruises at $11.6 \mathrm{~km}$ altitude where, compared to the surface, $\mathrm{O}_{4}$ "concentration" (square of the $\mathrm{O}_{2}$ concentration) is an order of magnitude lower. That is why the aerosols were neglected for estimating the cloud optical thickness (Sect. 3.2).

This renders the instrument's response for $\mathrm{O}_{4}$ much less sensitive to a change in local aerosol properties. The observed changes in the $\mathrm{O}_{4}$ column densities (Fig. 4, left) are mainly caused by the cloud cover as described in Sect. 3.2. Although $\mathrm{O}_{4}$ observations and intensity ratios (Fig. 4, right) at two wavelength intervals can be used here, the small corrections for the cloud cover and the aerosol layer at flight altitude can only be estimated. The $\mathrm{O}_{4}$ observation for both

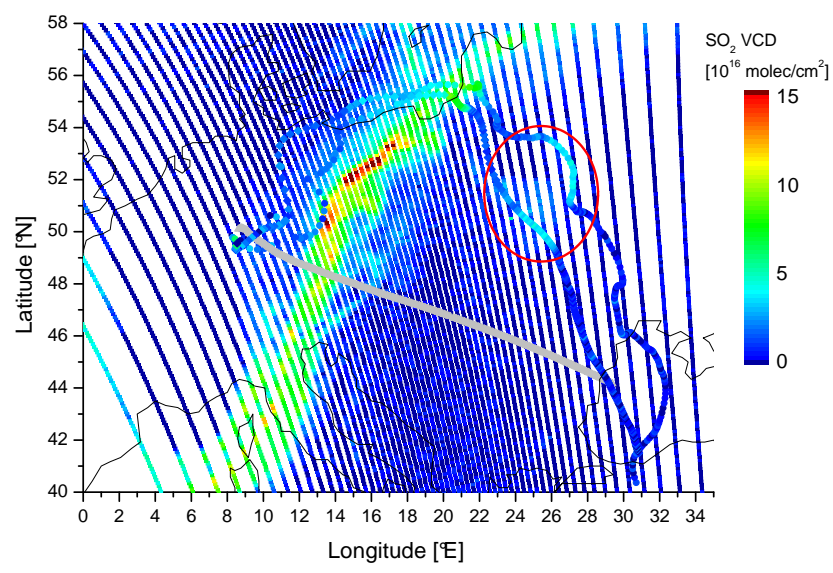

Fig. 13. Comparison of the CARIBIC data to the OMI satellite observation (http://disc.sci.gsfc.nasa.gov/Aura/data-holdings/OMI/ omso2_v003.shtml,march2010). In grey the flight track is shown and the CARIBIC and OMI VCDs are colour coded. Obviously the position of the small sub plume does not match for either the TRAJKS model (south) nor for the optimized wind speed (north). The main plume also does not match for neither of the models.

viewing directions, however, was dominated by the cloud. Therefore they were weighted less for the aerosol retrieval. Based on the intensity ratio measured by the upward $\left(+10^{\circ}\right)$ directed telescope, considering the fact that for the downward $\left(-10^{\circ}\right)$ telescope the intensity decreases during the first peak, the best approximation was an aerosol extinction of $k=$ $0.1 \mathrm{~km}^{-1}$ with $\omega=80 \%$ single scattering albedo (Fig. 14). The assumed aerosol layer extends from 11 to $12 \mathrm{~km}$, hence the total aerosol optical depth equals 0.1. Similar stratospheric aerosol optical densities were observed 5 months after the Mount Pinatubo eruption (Saunders, 1993).

The CARIBIC aerosol in situ real time measurements were limited to the size range from 14 to $100 \mathrm{~nm}$, thus not providing any information on the larger, optically active, aerosols. Therefore we consider independent measurements. Here a complication is that clouds also influence satellite based aerosol retrievals (e.g. OMI or GOME-2), and shield the aerosols from ground based observations e.g. LIDAR. However, in the vicinity of the clouds some information can be retrieved from combined OMI/MODIS observations (http://mirador.gsfc.nasa.gov/, June 2009). The total aerosol optical thickness next to the cloud was about 0.3 , however, no information about the altitude of the aerosols is given here. Probably most of the observed aerosols are situated at lower altitude levels, bearing in mind the uncertainty of the temporal shifts, this can only be used to estimate an upper limit for the AOT. The assumed single scattering albedo takes into account the enhanced carbon content in the volcanic aerosol (Martinsson et al., 2009), which usually leads to dark aerosols (Bond and Bergstrom, 2006). The aerosols here, however, are mixed with highly reflecting sulphurous aerosols and are about a week old. 


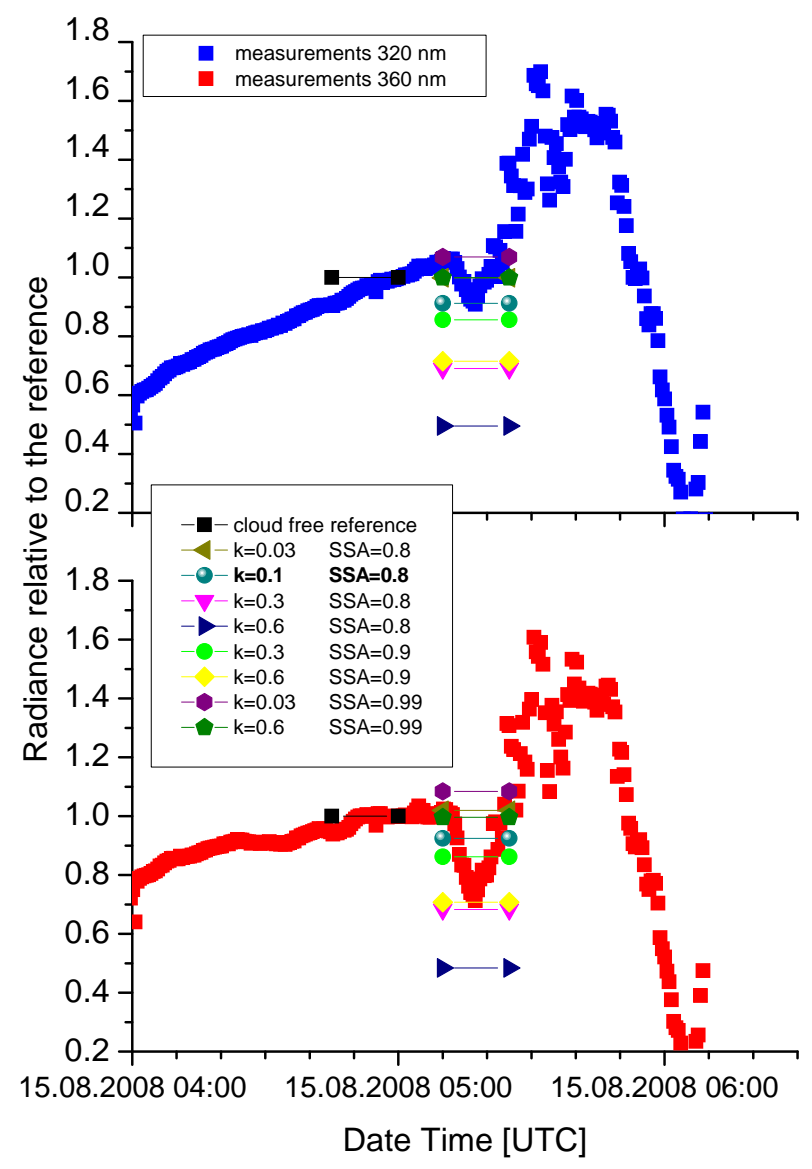

Fig. 14. Simulated and modelled intensity ratios for $-10^{\circ}$ telescope and the 320 and $360 \mathrm{~nm}$ range. Similar comparisons were made for the $-10^{\circ}$ telescope as well as for the dense cloud. In total the best agreement was observed if the aerosol extinction is assumed to be 0.1 and the $\mathrm{SSA}=0.8$. The clouds below the aerosol layer were included according to the results of Sect. 3.2.

The air mass factors for both instruments (CARIBIC DOAS and GOME-2) were simulated with the same cloud optical thickness i.e. 0.8 and 10 for the first and the second peak, respectively, using identical aerosol optical properties. While for CARIBIC the influence of the different clouds on the $\mathrm{SO}_{2} \mathrm{AMF}$ is almost negligible ( $1 \%$ increase for the dense cloud), the sensitivity for GOME-2 increases from 2.19 to 2.4 for nadir if a dense cloud cover is assumed, instead of the optically thin one. Compared to the geometrical approximation, the AMF hardly changes for the dense cloud, where the relative change is always less than $+3 \%$, depending on the viewing angle. On the other hand for the approximated thin cloud the AMF is reduced by $5 \%$ to $8 \%$ for the swath edge or the centre.

This rather slight increase in the AMF might be surprising, but with respect to the low air density at $205 \mathrm{hPa}$ (flight level) it can be understood that the geometrical approach is already a good approximation for the AMF. If a dense and bright cloud below the $\mathrm{SO}_{2}$ layer is included in the simulation, it mainly results in an increased intensity, but the light path in that layer is hardly extended. Even if a much brighter cloud is simulated ( $\mathrm{SSA}=0.9999)$ the effect only is about $10 \%$ relative to the geometrical approximation.

The dark aerosols $(\mathrm{SSA}=80 \%)$ lead to a reduced sensitivity for the altitude range between 11 and $12 \mathrm{~km}$ for both instruments. This effect is partly compensated by the bright surface of the cloud below (Fig. 1). However, if the cloud is optically thin and the instrument's viewing direction is close to nadir, this effect is smaller as for the other viewing directions, so that the AMF for the GOME-2 instrument is reduced over the thin cloud. For the pixels close to the swath edges the difference to the geometrical approximation is smaller $(\approx 5 \%)$. For both instruments the influence of other values for the aerosol optical thickness was simulated for both cloud coverages. A relative change in the AMF of $\pm 10 \%$ is modelled, when the aerosol optical thickness is varied between 0.03 and 0.3 , which is seen as the upper limit.

\subsection{Comparison}

A direct comparison of the CARIBIC and GOME-2 observations is shown in Fig. 15. While up to Sect. 4.4 the geometrical approximation for the GOME-2 AMF was used, here the estimated cloud optical thickness and aerosol extinction above the cloud are included in the simulation. The same settings were used for CARIBIC DOAS AMF from the beginning, and the lower flight altitude for the last two measurements above the cloud (11470 m and $11280 \mathrm{~m}$ ) was also considered.

Since the Lufthansa Airbus dived through the cloud and thereby terminated the CARIBIC DOAS observation of the volcanic $\mathrm{SO}_{2}$ at 05:48 UTC (Fig. 7), the horizontal extent of the plume differs between the two observational data sets. In and below the cloud the uncertainty in the CARIBIC DOAS data increases and also different air masses below and above the cloud are observed by CARIBIC and GOME-2. Hence west of $16^{\circ} \mathrm{E}$ (in the shifted data in Fig. 15) these datasets should not be compared.

The correlation depicted in Fig. 16, shows a good agreement between the CARIBIC and the GOME- 2 data. For this final comparison all CARIBIC data points situated in the same GOME-2 pixel, were averaged, thereby reducing the scatter. The offset of $8.3 \times 10^{13} \pm 2.05 \times 10^{15} \mathrm{molec} / \mathrm{cm}^{2}$ is almost negligible, the slope deviates from unity by $7.9 \%$ with an error of $8.1 \%$ only. This signifies excellent agreement between the two observations. The correlation is more or less independent of the assumed aerosol extinction above the cloud. Although the AMFs for both GOME-2 and CARIBIC vary up to $10 \%$, the correlations of the respective vertical columns show a slope between 1.02 and 1.08. This is a consequence of a similar influence of the aerosol layer on both DOAS observations. Also the offsets between the instruments and the correlation coefficients $\left(R^{2}\right)$ are similar. 


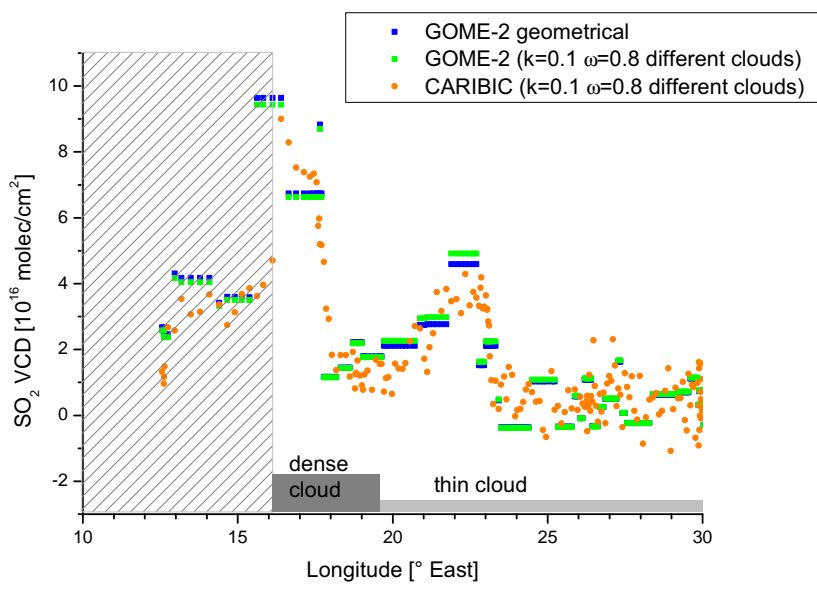

Fig. 15. Comparison of CARIBIC DOAS and GOME-2 $\mathrm{SO}_{2}$ vertical column densities. Besides the standard geometrical AMF for GOME-2, a more appropriate one was simulated, which is based on the cloud and aerosol properties estimated from the CARIBIC DOAS observations. The areas where the different clouds are considered for the AMFs are marked by the grey bars along the x-axes. The hashed area indicates the part of the flight where the Airbus was inside or below the cloud and different air masses are observed by the two instruments.

If the TRAJKS correction for the overpass time is assumed (Fig. 10), the slope decreases slightly to 0.98 and the offset increases to $2.46 \times 10^{15}$. Most of all, the correlation gets worse, the $R^{2}$ equals 0.77 and is therefore lower than for the optimised wind speed (Fig. 15) where it reaches 0.85 . This indicates that the correlation is dominated by the high vertical columns observed in the main plume and the background being close to zero.

\section{Conclusions}

CARIBIC has, for the deployment periods of near monthly flights in 1997-2002 and 2005-present, only twice observed increased particulate $\mathrm{S} / \mathrm{O}_{3}$ ratios due to volcanic eruptions. Of these two events, the Kasatochi eruption was by far the larger one (Martinsson et al., 2009). This fact is not so much due to the limited spatial coverage of CARIBIC but rather due to the rarity of explosive volcanic eruptions. Unlike research aircraft that can be launched and directed to study specific volcanic plumes in detail, CARIBIC observations of volcanic plumes occur more or less by chance, although in this case the flight repetition rate and choice of flight destination enabled us to follow the effect of Kasatochi over a period of several months (Martinsson et al., 2009).

CARIBIC and GOME-2 were not exactly simultaneously observing the plume over Europe, which forced us to take into account the advection of the plume with the wind in the time interval between the different observations. It has been shown that this basically is feasible, although we also showed

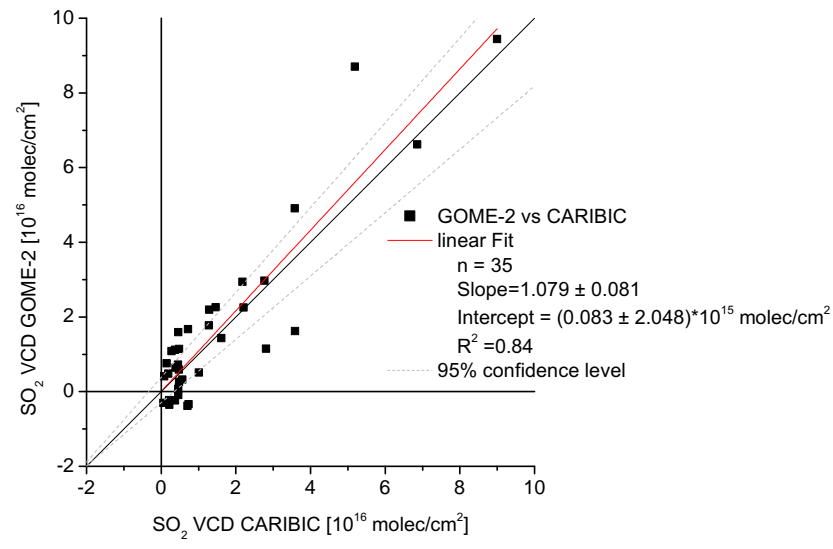

Fig. 16. Correlation plot of $\mathrm{SO}_{2}$ vertical columns observed by GOME-2 vs. averaged CARIBIC values. Only data where the aeroplane was clearly above the cloud are considered here (cf. Fig. 15).

that larger wind speeds than measured and modelled are needed to get an exact overlap. A good agreement between the observed spatial distributions was found if the wind speed is locally enhanced by $25 \%$. Due to the coarse spatial and temporal coverage the enhanced wind speed could not be supported by radio soundings in the critical region. The observed discrepancy to the trajectory model is only local and probably due to mesoscale variability close to the tropopause and the jet stream. Only limited information on the wind speed can be gained from the trace gas spatial distribution inside the main plume, here additional measurements were required.

Information on the aerosol optical thickness and the single scattering albedo retrieved from the DOAS is still uncertain. The deficiency could not be remedied by in situ measurements, since the optical particle counter was not running properly during this flight and additional instruments currently not included in CARIBIC would be necessary to measure the single scattering albedo. Also from independent observations only limited information could be gained. This lack of information results in a enhanced uncertainty, which has to be kept in mind for the comparison of CARIBIC and GOME-2 observations. However, the estimation of plume altitude and thickness is based on several observations and therefore we assume it to be correct, the cloud top altitude below the plume is also an important parameter and is supported by other CARIBIC observations. Because of that, no sensitivity studies for these parameters were included. The main remaining uncertainties are the correction of the wind speed and aerosol optical thickness. It turned out that the sensitivity of the overall correlation to the aerosol optical thickness is limited, although the vertical columns change by up to $10 \%$, while the wind speed mainly influences the quality of the correlation and has hardly any effect on the slope and background. 
Altogether, a very good and robust correlation between CARIBIC and GOME-2 observations was found, with a slope deviating from unity by less than $10 \%$.

The described observation also showed, that the integration of an in-situ $\mathrm{SO}_{2}$ instrument in the CARIBIC container would be a real benefit for the project. The instrument is currently under construction and is planned to be integrated in the future.

Acknowledgements. This paper is dedicated to Ulrich Platt for his 60th birthday.

We thank OMI team and the PIs Nikolay Krotkov and Arlin Krueger for providing the data at: http://disc.sci.gsfc.nasa.gov/ Aura/data-holdings/OMI/omso2_v003.shtml. We thank Andreas Waibel, Thomas Dauer, Sven Dankart and Detlev Hartwig and the entire Lufthansa Airlines and Lufthansa Technik and of course the CARIBIC Team for their commitment and support. The DOAS system was build and operated by the Institut für Umweltphysik of the Universität Heidelberg. Rinus Scheele is acknowledged for helping with the trajectory calculations. The development and operation of the CARIBIC system has been financially supported by the German Ministry of Education and Science (AFO 2000), by the European Commission's DGXII Environment RTD 4th, 5th and 6th Framework programs, by the Max-Planck-Society, EON-Ruhrgas and Frankfurt Airport.

The service charges for this open access publication have been covered by the Max Planck Society.

Edited by: A. Richter

\section{References}

Bogumil, K., Orphal, J., Voigt, S., Bovensmann, H., Fleischmann, O. C., Hartmann, M., Homann, T., Spietz, P., Vogel, A., and Burrows, J. P.: Reference Spectra of Atmospheric Trace Gases Measured the SCIAMACHY PFM Satellite Spectrometer, Proc. 1st Europ. Sympos. Atmos. Meas. from Space (ESAMS-99), ISSN 1022-6656, ESA-ESTEC, Noordwijk, 2, 443-447, 1999.

Bogumil, K., Orphal, J., Homann, T., Voigt, S., Spietz, P., Fleischmann, O. C., Vogel, A., Hartmann, M., Bovensmann, H., Frerik, J., and Burrows, J. P.: Measurements of Molecular Absorption Spectra with the SCIAMACHY Pre-Flight Model: Instrument Characterization and Reference Data for Atmospheric Remote-Sensing in the 230-2380 nm Region J. Photoch. Photobio. A, 157, 167-184, 2003.

Bond, T. C. and Bergstrom, R. W.: Light absorption by carbonaceous particles: an investigative review, Aerosol Sci. Tech., 40, 27-67, doi:10.1080/2786820500421521, 2006.

Bovensmann, H., Burrows, J. P., Buchwitz, M., Frerick, J., Noël, S., Rozanov, V. V., Chance, K. V, and Goede, A. P. H.: SCIAMACHY-Mission Objectives and Measurement Modes, J. Atmos. Sci., 56, 126150, 1999.

Brenninkmeijer, C. A. M., Crutzen, P., Boumard, F., Dauer, T., Dix, B., Ebinghaus, R., Filippi, D., Fischer, H., Franke, H., Frieß, U., Heintzenberg, J., Helleis, F., Hermann, M., Kock, H. H., Koeppel, C., Lelieveld, J., Leuenberger, M., Martinsson, B. G., Miemczyk, S., Moret, H. P., Nguyen, H. N., Nyfeler, P., Oram, D.,
O’Sullivan, D., Penkett, S., Platt, U., Pupek, M., Ramonet, M., Randa, B., Reichelt, M., Rhee, T. S., Rohwer, J., Rosenfeld, K., Scharffe, D., Schlager, H., Schumann, U., Slemr, F., Sprung, D., Stock, P., Thaler, R., Valentino, F., van Velthoven, P., Waibel, A., Wandel, A., Waschitschek, K., Wiedensohler, A., Xueref-Remy, I., Zahn, A., Zech, U., and Ziereis, H.: Civil Aircraft for the regular investigation of the atmosphere based on an instrumented container: The new CARIBIC system, Atmos. Chem. Phys., 7, 4953-4976, doi:10.5194/acp-7-4953-2007, 2007.

Bruns, M., Buehler, S. A., Burrows, J. P., Heue, K.-P., Platt, U., Pundt, I., Richter, A., Rozanov, A., Wagner, T. and Wang, P., Retrieval of Profile Information from Airborne Multi Axis UV/visible Skylight Absorption Measurements, Appl. Opt. 43, 22, 4415-4426, 2004.

Bussemer, M. , Der Ring-Effekt: Ursachen und Einflußauf die Messung stratospärischer Spurenstoffe, diploma thesis, Univ. of Heidelberg, Heidelberg, Germany, 1993.

Callies, J., Corpaccioli, E., Eisinger, M., Hahne, A., and Lefebvre, A.: GOME-2- Metops second-generation sensor for operational ozone monitoring, ESA Bull., 102, 28-36, 2000.

Deutschmann, T.: Atmospheric Radiative Transfer Modelling with Monte Carlo Methods, Diploma Thesis Universiät Heidelberg, 2009.

Dix, B., Brenninkmeijer, C. A. M., Frieß, U., Wagner, T., and Platt, U.: Airborne multi-axis DOAS measurements of atmospheric trace gases on CARIBIC long-distance flights, Atmos. Meas. Tech., 2, 639-652, doi:10.5194/amt-2-639-2009, 2009.

Frieß, U., Monks, P. S., Remedios, J. J., Rozanov, A., Sinreich, R., Wagner, T., and Platt, U.: MAX-DOAS $\mathrm{O}_{4}$ measurements: A new technique to derive information on atmospheric aerosols: 2. Modelling studies, J. Geophys. Res., 111, D14203, doi:10.1029/2005JD006618, 2006.

Gür, B., Spietz, P., Orphal, J., and Burrows, J.: Absorption Spectra Measurements with the GOME-2 FMs using the IUP/IFE-UBs Calibration Apparatus for Trace Gas Absorption Spectroscopy CATGAS, Final Report, IUP University of Bremen, Oct., 2005.

Grainger, J. and Ring, J.: Anomalous Fraunhofer line profiles, Nature, 193, p. 762, 1962.

Heue, K.-P.: Airborne Multi AXes DOAS instrument and measurements of two dimensional trace gas distribution, $\mathrm{Ph} . \mathrm{D}$. thesis, Universität Heidelberg, Germany, 2005.

Heue, K.-P., Richter, A., Bruns, M., Burrows, J. P., v. Friedeburg, C., Platt, U., Pundt, I., Wang, P., and Wagner, T.: Validation of SCIAMACHY tropospheric $\mathrm{NO}_{2}$-columns with AMAXDOAS measurements, Atmos. Chem. Phys., 5, 1039-1051, doi:10.5194/acp-5-1039-2005, 2005.

Irie, H., Kanaya, Y., Akimoto, H., Iwabuchi, H., Shimizu, A., and Aoki, K.: First retrieval of tropospheric aerosol profiles using MAX-DOAS and comparison with lidar and sky radiometer measurements, Atmos. Chem. Phys., 8, 341-350, doi:10.5194/acp-8341-2008, 2008.

Khelif, D., Burns, S. P., and Friehe, C. A.: Improved Wind Measurements on Research Aircraft, J. Atmos. Ocean. Tech., 16, 860-875 1999.

Kraus, S.: DOASIS - A Framework Design for DOAS, Shaker, 2006.

Levelt, P.F., van den Oord, G.H.J., Dobber, M.R., Mälkki, A., Visser, H., de Vries, J., Stammes, P., Lundell, J., and Saari, H.: The Ozone Monitoring Instrument, IEEE Trans. Geo. Rem. 
Sens., 44(5), 1093-1101, 2006.

Lohmann, U., Leaitch, W. R., Barrie, L., Law, K., Yi, Y., Bergmann, D., Bridgeman, C., Chin, M., Christensen, J., Easter, R., Feichter, J., Jeuken, A., Kjellström, E., Koch, D., Rasch, P., and Roelofs, G.-J.: Vertical distributions of sulfur species simulated by large scale atmospheric models in COSAM: comparison with observations, Tellus B, 53(5), 646-672, 2001.

Martinsson, B. G., Brenninkmeijer, C. A. M., Carn, S. A., Hermann, M., Heue, K.-P., van Velthoven, P. F. J., and Zahn, A.: Influence of the 2008 Kasatochi volcanic eruption on sulfurous and carbonaceous aerosol constituents in the lower stratosphere, Geophys. Res. Lett., 36, L12813, doi:10.1029/2009GL038735, 2009.

Nguyen, H. N., Gudmundsson, A., and Martinsson, B. G.: Design and calibration of a multi-channel aerosol sampler for tropopause region studies from the CARIBIC platform, Aerosol Sci. Tech., 40, 649-655, 2006.

Platt, U. and Stutz, J.: Differential Optical Absorption Spectroscopy, Principles and Applications, Springer Berlin Heidelberg, 2008.

Richter, A., Wittrock, F., Schönhardt, A., and Burrows, J. P.: Quantifying volcanic $\mathrm{SO}_{2}$ emissions using GOME-2 measurements, Poster presentation: EGU General Assembly, Vienna, Austria, AS3.15 XY247, available at: http://www.iup.uni-bremen.de/ doas/posters/egu_2009_richter.pdf, last access: 11 January 2010, 19-24 April 2009.

Saunders, R.: Radiative properties of Mount Pinatubo volcanic aerosols over the tropical Atlantic, Geophys. Res. Lett., 20, 137140, 1993.

Scheele, M. P., Siegmund, P. C., and van Velthoven, P. F. J.: Sensitivity of trajectories to data resolution and its dependence on the starting point: in or outside a tropopause fold, Meteorol. Appl., 3, 267-273, 1996.

Schuck, T. J., Brenninkmeijer, C. A. M., Slemr, F., Xueref-Remy, I., and Zahn, A.: Greenhouse gas analysis of air samples collected onboard the CARIBIC passenger aircraft, Atmos. Meas. Tech., 2, 449-464, doi:10.5194/amt-2-449-2009, 2009.

Stohl, A., Haimberger, L., Scheele, M. P., and Wernli, H.: An intercomparison of results from three trajectory models, Meteorol. Appl., 8, 127-135, 2001.

Theys, N., van Roozendael, M., Dils, B., Hendrick, F., Hao, N., and De Maziere, M.: First satellite detection of volcanic bromine monoxide emission after the Kasatochi eruption, Geophys. Res. Lett., 36, L03809, doi:10.1029/2008g1036552, 2009. van Roozendael, M., Loyola, D., Spurr, R., Balis, D., Lambert, J.-C., Livschitz, Y., Valks, P., Ruppert, T., Kenter, P., Fayt, C., and Zehner, C.: Ten years of GOME/ERS-2 total ozone data-The new GOME data processor (GDP) version 4: 1. Algorithm description, J. Geophys. Res., 111, D14311, doi:10.1029/2005JD006375, 2006.

Wang, P., Richter, A., Bruns, M., Burrows, J. P., Scheele, R., Junkermann, W., Heue, K.-P., Wagner, T., Platt, U., and Pundt, I.: Airborne multi-axis DOAS measurements of tropospheric $\mathrm{SO}_{2}$ plumes in the Po-valley, Italy, Atmos. Chem. Phys., 6, 329-338, doi:10.5194/acp-6-329-2006, 2006.

Wagner, T., Dix, B., von Friedeburg, C., Frieß, U., Sanghavi, S., Sinreich, R., and Platt, U.: MAX-DOAS $\mathrm{O}_{4}$ measurements: A new technique to derive information on atmospheric aerosols - Principles and information content, J. Geophys. Res., 109, D22205, doi:10.1029/2004JD004904, 2004.

Wagner, T., Burrows, J. P., Deutschmann, T., Dix, B., von Friedeburg, C., Frieß, U., Hendrick, F., Heue, K.-P., Irie, H., Iwabuchi, H., Kanaya, Y., Keller, J., McLinden, C. A., Oetjen, H., Palazzi, E., Petritoli, A., Platt, U., Postylyakov, O., Pukite, J., Richter, A., van Roozendael, M., Rozanov, A., Rozanov, V., Sinreich, R., Sanghavi, S., and Wittrock, F.: Comparison of box-airmass-factors and radiances for Multiple-Axis Differential Optical Absorption Spectroscopy (MAX-DOAS) geometries calculated from different UV/visible radiative transfer models, Atmos. Chem. Phys., 7, 1809-1833, doi:10.5194/acp-7-1809-2007, 2007.

Wagner, T., Beirle, S., and Deutschmann, T.: Three-dimensional simulation of the Ring effect in observations of scattered sun light using Monte Carlo radiative transfer models, Atmos. Meas. Tech., 2, 113-124, doi:10.5194/amt-2-113-2009, 2009.

Weissmann, M. and C. Cardinali, C.: The impact of airborne Doppler lidar measurements on ECMWF forecasts, Q. J. Rpy. Meteorol. Soc., 133, 107-116, 2007

Yang, K., Krotkov, N. A., Krueger, A. J., Carn, S. A., Bhartia, P. K., and Levelt, P. F.: Improving retrieval of volcanic sulfur dioxide from backscattered UV satellite observations, Geophys. Res. Lett., 36, L03102, doi:10.1029/2008GL036036, 2009. 